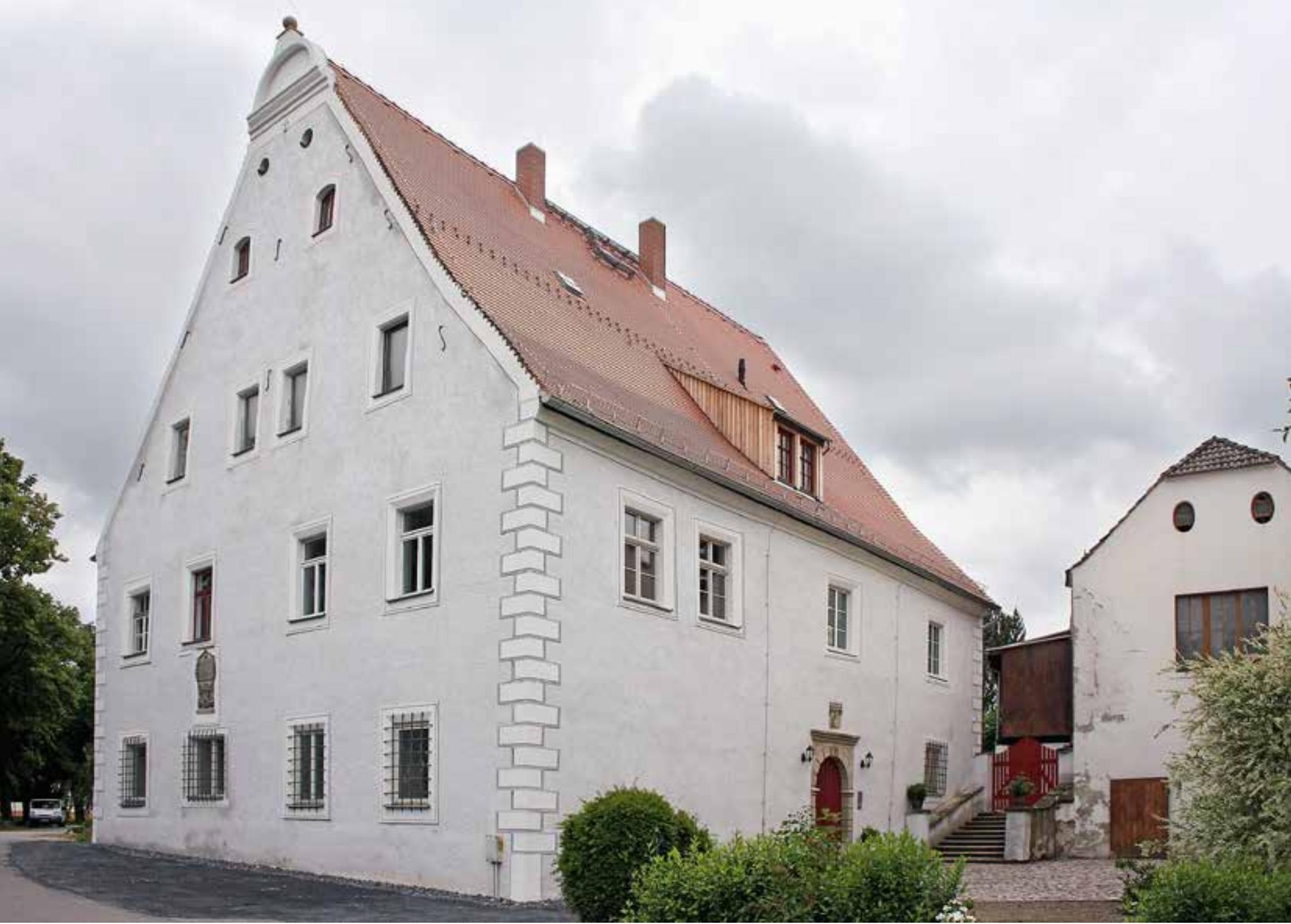

\title{
Das Rittergut Jahna in Niederjahna
}

\section{Matthias Donath}

Das Herrenhaus Niederjahna ist Sitz des Zentrums für Kultur//Geschichte und damit einer der Orte, an denen die „Sächsischen Heimatblätter" entstehen. Daher soll Niederjahna hier als typisches Rittergut der Lommatzscher Pflege vorgestellt werden. Das ist nicht ganz einfach, denn das Gutsarchiv Niederjahna wurde 1945 restlos vernichtet; im Hauptstaatsarchiv Dresden befinden sich nur Unterlagen, die bereits vor 1945 dorthin gelangt sind, etwa bei der Übertragung der Patrimonialgerichtsbarkeit an den sächsischen Staat, sowie die vom Lehnhof Dresden geführten Lehnsakten. ${ }^{1} 1937$ verfasste der Meißner Stadtarchivar Dr. Helmuth Gröger eine Geschichte des Ritterguts Jahna, die jedoch nie gedruckt wurde. ${ }^{2}$ Zum Glück ist das Manuskript erhalten geblieben; es ist heute eine wichtige Quelle, da es Inhalte des vernichteten Gutsarchives widerspiegelt. ${ }^{3}$ Leider ist auch sämtliches Inventar des Herren- hauses infolge der Bodenreform verloren gegangen; die Gemälde, unter anderem Porträts der Bewohner vom 17. bis 19. Jahrhundert, sind verschollen. Verloren sind auch alle historischen Ansichten, die es ehemals in Niederjahna gegeben haben muss; lediglich einige Fotos aus der Zeit zwischen 1920 und 1945 sind überliefert.

Seitdem ich 2010 das Herrenhaus Niederjahna erworben habe, versuche ich, die weitgehend ausgelöschte und vergessene Geschichte wieder ins Bewusstsein zu rufen. Der vorliegende Aufsatz ist das (Zwischen-)Ergebnis einer „Rekonstruktion“, bei der versucht wurde, durch Aufspüren von andernorts erhaltenem Archivgut, Zweitüberlieferungen usw. die Informationslücken zu schließen, die durch die Vernichtung des Gutsarchivs und die Enteignung und Vertreibung der Familie von Bischoffshausen entstanden sind.
Herrenhaus Niederjahna

Foto: Matthias Donath

1 Sächsisches Staatsarchiv, Hauptstaatsarchiv Dresden (folgend HStA Dresden), 10424, Grundherrschaft Niederjahna, sowie 10080, Lehnhof Dresden, hier Nr. O 3119 bis O 3130.

2 Helmuth Gröger: Jahna. Geschichte einer ritterlichen Herrschaft. Meißen 1937 (folgend Gröger 1937). Die Drucklegung war im Verlag der Truhe Fritz Pfeiffer in Meißen vorgesehen.

3 Erhalten ist der Durchschlag des Original-Manuskripts, eine Kopie befindet sich im Besitz von Dr. Matthias Donath. 
4 Ernst Gotthelf Gersdorf (Hrsg.): Urkundenbuch der Stadt Meißen und ihrer Klöster (Codex diplomaticus Saxoniae regiae II, 4), Leipzig 1873 (folgend CDS II, 4), Nr. 480.

5 Zur Dorf- und Flurform vgl. Karlheinz Blaschke/Susanne Baudisch: Historisches Ortsverzeichnis von Sachsen. Bd. 1. A-M. Leipzig 2006, S. 345.

6 Es handelt sich um die Urkunden im Hauptstaatsarchiv Dresden, 1001, Ältere Urkunden, O.U. 143 a und b, gedruckt in CDS II, 4, Nr. 147.

7 Thomas Ludwig: Die Urkunden der Bischöfe von Meißen. Diplomatische Untersuchungen zum 10 . bis 13 . Jahrhundert. Köln/Weimar/ Wien 2008, S. 70-87, vgl. auch Dirk Martin Mütze: Das Augustiner-Chorherrenstift St. Afra in Meißen (12051239). Leipzig 2016 (folgend Mütze 2016), S. 54-61.

8 Ernst Eichler/Hans Walther: Historisches Ortsnamenbuch von Sachsen. Bd. 1. A-L. Berlin 2001, S. 449-450. Eine aktuelle namenskundliche Bewertung hat Prof. Dr. Walter Wenzel vorgenommen, dem ich für seine Auskunft danke.

9 Mitunter wurde auch weiterhin von Niederjahna gesprochen.

10 Im Entwurf des Ritterguts zur Gemeindevereinigung heißt es: „Die Bezeichnung des Rittergutes Jahna als solches wird durch den Vertrag nicht berührt; die Gemeinde erkennt vielmehr an, daß diese Bezeichnung auch fernerhin dem Rittergut zusteht, auch wenn die Gemeinde infolge Vereinigung mit einer anderen Gemeinde ihre Selbstständigkeit verlieren sollte." Die Gemeinde hatte vorgeschlagen: „Das Rittergut trägt in Zukunft gleich wie die Gemeinde den Namen Niederjahna." In der letztlich vereinbarten Fassung heißt es: „Die Bezeichnung des Rittergutes als solches wird durch den Vertrag nicht berührt." Vgl. HStA Dresden, 10760, Amtshauptmannschaft Meißen, Nr. 751.

11 Niederjahna wurde 1926 mit Ober- und Niedermeisa zur Gemeinde Meisatal vereinigt und mit dieser 1928 in die Stadt Meißen eingemeindet. 1937 erfolgt die Umgliederung zur Gemeinde Jahna.

$12 \mathrm{Zu}$ Niederjahna im Besitz der Burggrafen vgl. Traugott

\section{Dorflage und Ortsname}

Das Dorf Niederjahna liegt westlich von Meißen an der alten Landstraße, die von Meißen nach Lommatzsch führt. Diese Straße durchzieht das Meisatal und erreicht dann die Anhöhe des Großen Jahneberges. Von dort führt die Straße hinunter ins Jahnabachtal, wo sie unmittelbar an Park und Garten des Ritterguts Jahna vorbeiführt. Dieses liegt in der Aue des Jahnabaches, jedoch nicht unmittelbar im Talgrund, sondern westlich des Baches am Rand eines ansteigenden Hanggeländes. Der Jahnabach, der nicht mit der Jahna zu verwechseln ist, die bei Riesa in die Elbe mündet, entspringt zwischen den Dörfern Mehren und Oberjahna. Sein Name - 1469 lautete er „Kaynbach“ - leitet sich vom Ortsnamen her. ${ }^{4}$ Der Jahnabach hat in den Elbtalhang links der Elbe ein tiefes Tal eingeschnitten und mündet nach sieben Kilometern in die Elbe. Das Waldstück dort, an dem sich eine Häuslersiedlung mit zwei Mühlen herausbildete, wird als Keilbusch bezeichnet.

Niederjahna ist eine Gutssiedlung mit Gutsblockflur. ${ }^{5}$ Der Ort, im Kern ein Rundweiler, ist slawischen Ursprungs. 2005 hielten Niederjahna und zahlreiche Orte der Umgebung 800-Jahrfeiern ab. Das Jubiläum bezog sich auf die Ersterwähnungen dieser Orte in der Stiftungsurkunde des Augustiner-Chorherrenstift St. Afra von 1205. In zwei von fünf Ausfertigungen der bischöflichen Stiftungsurkunde wird der Zehnt „.in beiden Jahna“ (,in utroque Kanin“) dem Stift St. Afra zugesprochen. ${ }^{6}$ Inzwischen ist jedoch bekannt, dass die Urkundenfassung, die den Besitz von St. Afra ausführlich wiedergibt, eine Fälschung darstellt. ${ }^{7}$ Als Originale sind zwei Urkunden des Bischofs Dietrichs II. von Meißen anzusprechen, die deutlich kürzer sind und nur wenige Orte nennen, die dem Stift als Besitz übertragen wurden. „Kanin“ fehlt in dieser Fassung. Bei den Urkunden mit den ausführlichen Besitzlisten handelt es sich um Fälschungen aus der Mitte des 13. Jahrhunderts. Insofern liegt für Niederjahna - wie für andere Dörfer der Lommatzscher Pflege auch - kein konkretes Jahr der Ersterwähnung vor. Der Zehnt aus Nieder- und Oberjahna wurde offenbar erst nach 1205 den Augustiner-Chorherren übertragen, was man durch die Urkundenfälschung zurückdatierte und abzusichern versuchte.

Mit den „beiden Jahna“ sind die Nachbardörfer Oberjahna (früher auch Großjahna) und Niederjahna (früher auch Kleinjahna) gemeint. Der Name leitet sich vom altsorbischen „Kanin“ ab und bedeutet „Siedlung des Kanja“. ${ }^{8}$ Der Personenname stammt von der Vogelbezeichnung „kanja“ ab, was „Weihe, Milan“ bedeutet. Die an- lautende Schreibung mit K- blieb bis ins 16. Jahrhundert erhalten, während das a zu ai/ay verändert wurde. So entstand die Schreibweise „Nyder Khayne“, wie sie in der durch Abschrift überlieferten Lehnsurkunde von 1486 bezeugt ist. Im 16. Jahrhundert veränderte sich der Anlaut von $\mathrm{K}-\mathrm{zu}$ J-, wohl in Anlehnung an das Dorf Jahna (Gemeinde Ostrau), während sich der Umlaut ai/ay wieder zum Vokal a zurückbildete.

Obwohl Ober- und Niederjahna beide zum Pfarrbezirk der Kirchgemeinde St. Afra in Meißen gehörten, nahmen sie doch jeweils eine eigenständige Entwicklung. Oberjahna war Eigentum des Augustiner-Chorherrenstifts St. Afra und unterstand nach dessen Auflösung teils dem Schulamt Meißen, das den Betrieb der Fürstenschule St. Afra sicherstellte, und teils dem Erbamt Meißen. Dagegen bestand in Niederjahna ein Herrensitz, aus dem sich ein Rittergut entwickelte. Obwohl beide Orte benachbart im Tal des Jahnabaches liegen, sind sie erst seit 1937 in einer Gemeinde vereint. Gleichwohl trug das Rittergut in Niederjahna mindestens seit dem 17. Jahrhundert den amtlichen, Oberjahna mit vereinnahmenden Namen Jahna. ${ }^{9}$ Beim Lehnhof Dresden war es als „Fidei Commiss Guth Jahna“ registriert. Dagegen führte das Rittergut in Jahna bei Ostrau den Namen „Goldhausen“, was aber nicht verhinderte, dass es zwischen beiden Rittergütern mehrfach Verwechslungen gab.

Als 1923 der Gutsbezirk Jahna in die Gemeinde Niederjahna eingemeindet wurde, legte die letzte Gutsherrin Margarethe Freifrau von Bischofshausen großen Wert darauf, dass der Name Jahna weiter geführt werden durfte, während die Gemeinde eine Umbenennung in Niederjahna vorschlug. ${ }^{10} 1935$ bildeten fünf Dörfer um Oberjahna die Gemeinde Jahna, der 1937 auch Niederjahna angegliedert wurde. ${ }^{11}$ Auch die 1952 gegründete LPG, die erste LPG in Sachsen, nutzte den Namen Jahna. Die Gemeinde wurde 1969 zu Jahna-Kagen und 1974 zu Jahna-Löthain erweitert. Infolge der Auflösung der LPG Jahna 1990/91 und der Angliederung von Jahna-Löthain an die Gemeinde Käbschütztal 1994 geriet der Name Jahna weitgehend außer Gebrauch.

\section{Die Burggrafen von Meißen in Niederjahna}

Ober- und Niederjahna waren, wie der Ortsname andeutet, slawische Siedlungen, doch ist über die slawische Besiedlung nichts weiter bekannt. In Niederjahna muss sich früh, vielleicht schon im 12. Jahrhundert, ein Herrensitz mit Gutshof herausgebildet haben, der sich im Besitz der Meinheringer, der Burggrafen von Mei- 
ßen, befand. ${ }^{12}$ Der älteste Beleg dafür ist eine Urkunde vom 30. Januar 1309, welche das Leibgedinge der Burggräfin Sophia, der Witwe des Burggrafen Meinhers III., bestätigt. Als Witwengut werden zwei Allode genannt, zu Barmenitz bei Lommatzsch und in Jahna („Allodia, videlicet in Pormytz et Canyn“). ${ }^{13}$ Ein Allodium oder Allod war ein freier Besitz, hier wohl zu übersetzen als Wirtschaftshof, den die Burggrafen nicht als Lehen vergaben, sondern in Eigenbesitz hatten. Auch im Zinsregister des Stifts St. Afra in Meißen erscheint das Allodium der Burggrafen („de allodio burcgraviorum“) in Kleinjahna (,in minori Kanyn“), welches 4 1/2 Schock (wohl bezogen auf Malter Roggen) Getreidezins $\mathrm{zu}$ entrichten hatte. ${ }^{14}$ Wahrscheinlich war der Hof in Niederjahna zwischenzeitlich verlehnt. Der älteste namentlich bekannte Bewohner des Hofes in Niederjahna ist Werner von Jahna, der in einer Urkunde vom 21. März 1320 ausdrücklich als Vasall (Lehnsmann) des Burggrafen Hermanns III. von Meißen erscheint („Wernhero de Kanyn, vasallo nostro"). ${ }^{15}$ Es ist nicht bekannt, welchem Geschlecht des niederen Adels er angehörte. ${ }^{16}$

Das älteste bauliche Zeugnis ist ein heute nicht mehr zugänglicher Raum mit Tonnengewölbe unter dem Erdgeschoss des Herrenhauses, der älter als das um 1580 erbaute Herrenhaus ist. Zum ursprünglichen Bestand gehören die $\mathrm{Au}$ ßenmauern und das Gewölbe, soweit diese aus Bruchstein bestehen. Beim Bau des heutigen Herrenhauses erfolgten Eingriffe durch den Bau eines neuen Fundamentstreifens, verbunden mit einer Verkürzung des Gewölberaums und dem Einbau einer Ziegelkappe. Im Zwickel über der Bruchstein-Einwölbung wurde 2011/12 Keramik des 14. Jahrhunderts geborgen. ${ }^{17}$ Außen entdeckten die Archäologen beim Abbruch eines neuzeitlichen Toilettenanbaus eine Grube mit Keramik des 14. Jahrhunderts, die von der südlichen Außenmauer des Herrenhauses durchschnitten wurde. Insgesamt lassen die Befunde den Schluss zu, dass sich am Standort des heutigen Herrenhauses ein steinerner Wohnturm befand, der um 1580 überbaut wurde. Dabei erfolgte im Westen und Süden eine Geländeregulierung durch Anschüttungen, so dass aus dem vermutlich ehemals freistehenden steinernen Kernbau der Teil eines Kellergeschosses wurde. Das nach Osten abfallende Gelände vor der Südfassade wurde begradigt. Die Vermutung, die Insel im nahen Inselteich sei Standort der mittelalterlichen Burg gewesen, hat sich nicht bewahrheitet, da nachgewiesen werden konnte, dass diese Insel erst nach 1801 als Teil eines romantischen Landschaftsparks geschaffen worden ist. Die Teiche sind auf den ältesten überlieferten Karten noch nicht vorhanden und vermutlich erst im 17. Jahrhundert angelegt worden.

\section{Die Familien Kundige, von Honsberg und Mönch in Niederjahna}

Spätestens 1406 verlehnten die Burggrafen von Meißen ihren Hof in Niederjahna an Sebenicz Kundige, einen Angehörigen der niederadligen Familie Kundige, die in der Umgebung Dresdens verschiedenen Grundbesitz innehatte. Er wird 1406 als „Sebenicz Kundige czur Kanen gesessin“ genannt. ${ }^{18} 1414$ ist „Nickil Kundige von der Gane“ bezeugt. ${ }^{19}$ Er und sein Bruder Dietrich (Dietz) verkauften den Rittersitz vor dem 17. Mai 1420 an Dietrich von Honsberg auf Lichtenwalde. Das geht aus zwei Urkunden des Jahres 1420 hervor, in denen Nickel und Dietz Kundige als ehemalige Besitzer genannt werden (,Nigkel und Ticze Kundigen eczwannne gesessen zcu der Kayne“). ${ }^{20}$

Dietrich von Honsberg, dessen Name aus der Belehnung von 1437 erschlossen werden kann, gehörte einer Patrizierfamilie aus Freiberg an, die in den niederen Adel hineingewachsen war. Er ist in den Listen der wettinischen Kanzlei aus den Jahren 1426/28 und 1435 eingetragen, aus denen hervorgeht, welche Lehnsleute der Burggrafen von Meißen an die Markgrafen von Meißen übergingen. ${ }^{21}$ Denn 1426 war mit Burggraf Heinrich II. von Meißen das Geschlecht der Meinheringer im Mannesstamm ausgestorben. Sogleich übernahm Friedrich der Streitbare (1370-1428), der erste Kurfürst von Sachsen aus dem Geschlecht der Wettiner, den burggräflichen Besitz nahe Meißen. ${ }^{22}$ Damit gelangte auch der Rittersitz Jahna unter die Lehnshoheit der Wettiner.

Kurfürst Friedrich II. von Sachsen (1412-1464) belehnte 1437 Conrad Mönch und seine Brüder mit Jahna sowie zwei Weinbergen in Zitzschewig. Conrad Mönch muss den Besitz zuvor von Dietrich von Honsberg erworben haben. Der älteste Lehnbrief ist in einem Kopiale im Hauptstaatsarchiv Dresden überliefert. ${ }^{23}$ Das thüringische Adelsgeschlecht Mönch (heutige Namensform von Münch) stammte aus der Grafschaft Camburg und lässt sich seit 1180 urkundlich nachweisen. ${ }^{24}$ Wichtigster Besitz war Gosserstädt im Weimarer Land, seit dem 16. Jahrhundert nach der Familie Münchengosserstädt genannt. Die Familie gehörte zu den führenden Geschlechtern des niederen Adels im thüringischen Landesteil der wettinischen Länder. Wiederholt leiteten Familienmitglieder wettinische Ämter an der Saale, etwa die Ämter Alltstedt, Jena, Weimar und Weida. ${ }^{25}$ Der meißnische
Märcker: Das Burggrafthum Meissen. Ein historisch-publicistischer Beitrag zur sächsischen Territorialgeschichte. Leipzig 1842 (folgend Märcker 1842), S. 177-178.

13 Märcker 1842, S. 438-439, Nr. 38.

14 CDS II, 4, Nr. 293, S. 186.

15 Märcker 1842, S. 444, Nr. 45. 16 Zahlreiche Zuordnungen des Beinamens „de Gana" beziehen sich auf Jahna bei Ostrau und nicht auf Niederjahna bei Meißen. So hat der 1205 bezeugte Heidenreich von Jahna, den Gröger 1937, S. 10 mit Niederjahna in Verbindung brachte, nichts mit unserem Jahna zu tun. Ebenso irrte Harald Schieckel. der den 1206 als Zeugen aufgeführten „Robertus de Gane“ auf Niederjahna bezog, vgl. Hubert Ermisch (Hrsg.): Urkundenbuch der Markgrafen von Meißen und Landgrafen von Thüringen 1196-1234 (Codex diplomaticus Saxoniae regiae I, A, 3). Leipzig 1898, Nr 100, Harald Schieckel: Herrschaftsbereich und Ministerialität der Markgrafen von Meißen im 12. und 13. Jahrhundert. Untersuchungen über Stand und Stammort der Zeugen markgräflicher Urkunden. Köln/Graz 1956, S. 74-75, 138. „Gana“ mit Gdeutet meist auf Jahna bei Ostrau hin. Zur Familie von Jahna aus Jahna bei Ostrau vgl. Dieter Rübsamen: Kleine Herrschaftsträger im Pleißenland. Studien zur Geschichte des mitteldeutschen Adels im 13. Jahrhundert. Köln/Wien 1987, S. 139 , 141, 146, 287 , $289,315,389,414,433,435$, $441,443,505$.

17 Während der Sanierungsarbeiten führte das Landesamt für Archäologie 2011/12 baubegleitende archäologische Untersuchungen durch. Die Ergebnisse sind dokumentiert im Kurzaktivitätsbericht NJA05 , erstellt am 29. Oktober 1912 von O. Spitzner. Auch die im Folgenden genannten Ergebnisse sind diesem Bericht entnommen.

18 Ernst Gotthelf Gersdorf (Hrsg.): Urkundenbuch des Hochstifts Meißen Bd. 2 (Codex diplomaticus Saxoniae regiae II, 2), Leipzig 1865 (folgend CDS II, 2), Nr. 792.

19 Thomas Kübler/Jens Klingner/Jörg Oberste (Hrsg.) Die Stadtbücher Dresdens (1404-1535) und Alten- 
dresdens (1412-1528). Bd. 1. Die drei ältesten Stadtbücher Dresdens (1404-1476). Leipzig 2007, S. 123, Nr. 117.

20 Hubert Ermisch/Beatrix Dehne (Hrsg.): Urkunden der Markgrafen von Meißen und Landgrafen von Thüringen 1419-1427 (Codex diplomaticus Saxoniae I, B, 4). Leipzig/Dresden 1941, Nr. 78 (17. Mai 1420) und Karl Freiherr von Posern-Klett (Hrsg.): Urkundenbuch der Städte Dresden und Pirna (Codex diplomaticus Saxoniae regia II, 5). Leipzig 1875 (folgend CDS II, 5), Nr. 164 (3. September 1420). Vgl. auch Joachim Schneider: Spätmittelalterlicher deutscher Niederadel. Ein landschaftlicher Vergleich. Stuttgart 2003 (folgend Schneider 2003), S. 164, Fußnote 169.

21 Schneider 2003, S. 204-205.

22 Schneider 2003, S. 200-202.

23 HStA Dresden, 10004, Kopiale, Nr. 35, Bl. 114r, vgl. Lothar Clemens von Hausen: Vasallen-Geschlechter der Markgrafen zu Meißen, Landgrafen $\mathrm{zu}$ Thüringen und Herzöge zu Sachsen bis zum Beginn des 17. Jahrhunderts. Berlin 1892, S. 314; Peter Wiegand: Die Hieronymusgesellschaft Kurfürst Friedrichs II. von Sachsen. Antihussitisches Selbstverständnis und herrschaftliche Integration im Spiegel einer wettinischen Hofstiftung von 1450. In. Neues Archiv für sächsische Geschichte 87 (2016), S. 59-120 (folgend Wiegand 2016), hier S. 119.

24 Hausen 1892, S. 314-315. Simon und Valentin Mönch, die laut dem Zinsregister von St. Afra über Bauernhöfe in Stroischen verfügten, waren nicht mit Conrad Mönch verwandt, vgl. CDS II, 4, Nr. 239, S. 188.

25 Christian Hesse: Amtsträger der Fürsten im spätmittelalterlichen Reich. Die Funktionseliten der lokalen Verwaltung in Bayern-Landshut, Hessen, Sachsen und Württemberg 1350-1515. Göttingen 2005 (folgend Hesse 2005), S. 120, 221, 222, 615, $621,630,656$.

26 Hesse 2005, S. 615 .

27 CDS II, 4, Nr. 86. „Hauptmann“ ist hier als Synonym zu „Amtmann“ zu verstehen.

28 HStA Dresden, 10004, Kopiale, Nr. 40, Bl. $188 \mathrm{v}$.

29 CDS II, 4, Nr. 96.
Zweig stammt von Conrad Mönch dem Älteren ab. Dieser war 1425/26 und 1431 bis 1435 Vogt (Amtmann) in Mühlberg, zwischenzeitlich 1430 bis 1435 Vogt in Torgau sowie 1426 bis 1428 und 1436 bis 1438 Hauptmann (Amtmann) des Amtes Meißen. ${ }^{26}$ Während seiner Dienstzeit in Meißen erwarb „Conrad Monch houptman zcu Missin“27 das Rittergut Jahna, womit sich die Familie Mönch in der Mark Meißen ansiedelte.

Conrad Mönch war mit einer Ilse (Elisabeth) verheiratet. 1441 wurde ein Leibgedingebrief ausgestellt, der Ilse für den Fall, dass ihr Mann vor ihr sterben sollte, „die Koyne“ sowie das Dorf Nimtitz als Witwengut (Leibgedinge) zusprach. ${ }^{28}$ In einer Urkunde vom 13. September 1443 erscheint Conrad Mönch mit dem Besitzvermerk „czu der Kayn“29 und 1447 in einem Amtsassenverzeichnis des Amtes Meißen als Herr über das „Forwerck zcur Kane“.30 1457 stiftete derselbe zwei Seelenmessen in der St. Afrakirche. ${ }^{31}$ In der Urkunde wird auch der Sohn Conrad der Jüngere genannt, der bei einer Lehnsaufteilung 1458 den Rittersitz in Niederjahna übernahm. ${ }^{32} 1469$ erscheint er als „Kuncze Monnich zcum Kayne gesessen“, 1470 als „Conrado Monch in Kain“ und 1477 als „Cuntz Monch czur Kayn“. ${ }^{33}$

Conrad Mönch war Mitglied der 1450 von Kurfürst Friedrich II. von Sachsen gestifteten Hieronymusgesellschaft. ${ }^{34}$ Diese Adelsgesellschaft hatte eine deutliche antihussitische Ausrichtung, ihr gehörten neben dem Kurfürsten überwiegend Männer des niederen Adels an, die als „adlige Funktionseliten“ beschrieben werden können. Eine um 1460 verfasste Mitgliederliste der Hieronymusgesellschaft verzeichnet „Conrat Monich der jungere“. ${ }^{35}$

Conrad Mönch der Jüngere starb im Jahr 1486, denn am 30. Oktober 1486 stellte Herzog Albrecht von Sachsen den Söhnen Nickel (Nikolaus), Heinrich und Wolfgang Mönch einen Lehnbrief aus. ${ }^{36}$ Der in Abschrift erhaltene Lehnbrief belegt, dass „Nyder Khayne“ ein voll ausgebildetes Rittergut mit zugehörigen Dörfern und Dorfteilen, Gerichtsbarkeit und Ritterdiensten war. Bereits am 19. Juni 1486 hatte Herzog Albrecht der Familie Mönch eine Belehnung ,zur gesamten Hand“ ausgestellt.

Heinrich Mönch, einer der drei Brüder, schied aus der Belehnung aus, weil er in den geistlichen Stand trat. Er war von 1498 bis 1508 Propst des Nonnenklosters in Mühlberg ${ }^{37}$ und wurde um 1510 in das Domkapitel zu Meißen aufgenommen. $^{38} 1517$ stiftete der Domherr in der St. Afrakirche ein Jahrgedächtnis für sich und seine Familie. ${ }^{39}$ Der Lehnbrief Herzog Georgs vom 16. Juni 1501 wurde auf die Brüder
Nickel und Wolfgang Mönch ausgestellt. Nickel hatte zwei Söhne, Heinrich und Nickel (Nikolaus). Letzterer trat in das Augustiner-Chorherrenstift St. Afra ein, jedoch nach 1504 wohl wieder aus. $^{40}$ 1525/26 starb Nickel Mönch der Ältere, denn am 23. Februar 1526 belehnte Herzog Georg Nickels Sohn Heinrich Mönch mit Niederjahna. Dieser empfing noch 1540 und 1554 Lehnsurkunden. Er starb 1565 und wurde von seinen Söhnen Christoph, Gebhard und Wolf beerbt, die sich auf eine Aufteilung des Erbes einigten. Dabei übernahm Gebhard Mönch, der mittlere Sohn, das Rittergut Jahna, mit dem er am 23. August 1572 alleine belehnt wurde. Schulden zwangen ihn, diesen Besitz 1579 an Hans von Schleinitz auf Schieritz zu verkaufen, der bereits 1565 das Meißner Haus der Brüder Mönch erworben hatte. Mit der Familie von Schleinitz, die unmittelbar nach dem Besitzübergang das noch vorhandene Herrenhaus errichten ließ, begann die neuzeitliche Geschichte des Ritterguts Jahna.

\section{Herrschaftsbezirk und -rechte}

Erst in der zweiten Hälfte des 16. Jahrhundert bildete sich der Besitzumfang des Ritterguts Jahna heraus, wie er bis zu den Agrarreformen des 19. Jahrhunderts Bestand haben sollte. Über den Herrschaftsbezirk und die Untertanen geben die Lehnbriefe, die Steuerregister ${ }^{41}$, eine Aufstellung aus dem Jahr $1611^{42}$ sowie der Ablösungsrezess aus dem Jahr $1841^{43}$ Auskunft. Im Amtserbbuch des Amtes Meißen von 1547 ist Niederjahna hingegen nicht eingetragen. ${ }^{44}$

Niederjahna: Niederjahna war ein reines Gutsdorf. Es gab außer dem Rittergut keine Bauernhöfe. ${ }^{45}$ Im Lehnbrief von 1486 ist nur vom „Hoff daselbst“ die Rede. Außerdem lebten hier Gärtner und Häusler. Die Anzahl der Häusler erhöhte sich im 16. Jahrhundert von drei (1509) auf fünf (1529, 1547, 1551), darunter ein Müller und ein Gastwirt. 1611 waren es sieben Gärtner und elf Häusler. 1693 hatte sich daran nichts geändert, nur war ein Haus unbewohnt. 1759 waren es wieder elf Häusler, aber nun schon acht Gartennahrungsbesitzer. Als Gärtner galten der Besitzer der Obermühle, der Niedermühle, der Erbschenke sowie fünf Dreschgärtner. 1841 zählte man acht Gärtner und nur noch neun Häusler. ${ }^{46}$ Die Zahlen machen deutlich, dass sich an der Bebauung und sozialen Gliederung des Dorfes über Jahrhunderte nur wenig änderte. Das Rittergut hatte die niedere und obere Gerichtsbarkeit inne („mit gerichten vber Hals und Hant“).

Jahnaischer Hof in Meißen: Der Jahnaische Hof ist aus vier Hausgrundstücken entstanden. ${ }^{47}$ Der älteste Teil ist das noch erhaltene Ge- 


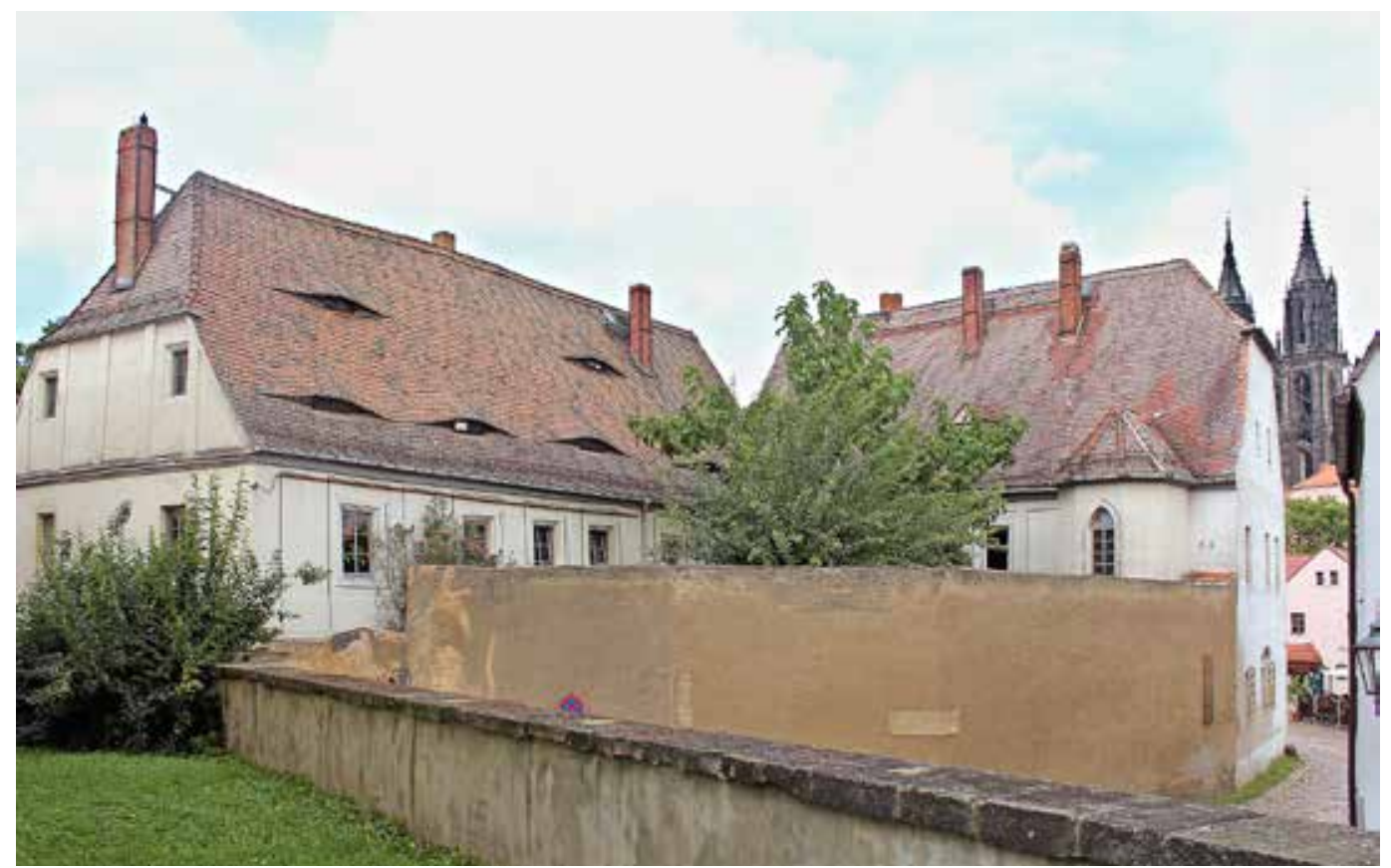

bäude des Maltitzer Hofs oberhalb des Hohlwegs. 1449 war dieser Hof an Heinrich und Hans von Maltitz gelangt. In der Mitte des 16. Jahrhunderts gehörte das Anwesen Heinrich von Maltitz auf Ilkendorf. Seine Witwe Margarethe von Maltitz verkaufte den Maltitzer Hof an Wolf Mönch, der 1554 starb, womit das Haus an seinen Bruder Heinrich Mönch auf Jahna gelangte. 1565 veräußerten dessen Söhne diesen Hof aufgrund von Schulden für $200 \mathrm{Gul}-$ den an Hans von Schleinitz auf Schieritz. 1568 erwarb derselbe Hans von Schleinitz durch einen Tausch zwei ehemalige Vikarienhäuser an der südlichen Grundstücksgrenze. Diese wurden später abgebrochen. Der nördliche Grundstücksteil war ehemals im Besitz des Augustiner-Chorherrenstifts St. Afra. Hier befanden sich Waschhaus und Viehhof. Das mit einem Haus bebaute Eckgrundstück überließ der Konvent des Afrastifts 1441 Heinrich von Schleinitz. Seitdem blieb dieses Eckhaus, genannt Schleinitzer Hof, im Besitz der Familie von Schleinitz. Hans von Schleinitz auf Schieritz, der 1579 das Rittergut Jahna erworben hatte, kaufte 1589 von der Witwe des Wolf Albrecht von Schleinitz auf Cavertitz den Schleinitzer Hof. Er führte alle Grundstücksteile zusammen und ließ 1609/10 ein neues Freihaus errichten, den Jahnaischen Hof, Freiheit 1 in Meißen. ${ }^{4}$ Seitdem blieben beide Besitzteile, das Rittergut und der Freihof in Meißen, immer in der gleichen Hand - bis 1945. Der Freihof wurde vom Lehnhof Dresden als separates Lehen geführt. Er gehörte nicht zum Rittergut Jahna, war aber mit diesem ein Teil des 1716 gestifteten Fideikommisses Jahna.
Nimtitz: Nimtitz war bereits 1441 Bestandteil des Rittergutes Niederjahna. In diesem Jahr erhielt Ilse Mönch einen Leibgedingebrief, der ihr als Witwengut den Rittersitz Niederjahna und das Dorf Nimtitz zusicherte. Auch im Lehnbrief von 1486 gehörte das Dorf Nimtitz, damals wohl das ganze Dorf, mit niederer Gerichtsbarkeit zum Rittergut Jahna. Nach dem Amtserbbuch von 1547 gehörten aber nur noch neun der zehn Grundeigentümer zum Rittergut Jahna, einer unterstand Gottschalk von Haugwitz auf Hirschstein. 1611 waren 4 Bauern, 3 Gärtner und 2 Häusler zinspflichtig. 1841 wurden die Dienstpflichten von 3 Bauern und 7 Gärtnern abgelöst. Die eine Bauernstelle, die 1547 dem Rittergut Hirschstein zugeordnet war, gelangte später an das Rittergut Löthain.

Questenberg: In sämtlichen Lehnbriefen seit 1486 umfasst die Belehnung auch Weinberge, Äcker und Gärten vor der Stadt Meißen. Auch in den Steuerregistern wurden zahlreiche Bewohner „vor Meißen“ dem Rittergut Jahna zugeordnet. Dem Rittergut gehörten jene Fluren an, die später nach einem der Weinberge als Questenberg bezeichnet wurden. Dort bestand eine Häuslerzeile. 1547 gab es in Questenberg 22 Häusler, die nach Niederjahna zinsten.

Korbitz: Das Vorwerk Korbitz wurde vermutlich ausgehend von Niederjahna als vorgelagerter Wirtschaftshof angelegt. Conrad Mönch urkundete 1471 als „,erblehenherre des forwerckes zcu Korwitz“.49 Damals war der Hof oder ein Teil desselben an Peter Seifart verlehnt. 1504 Korbitz für 1.090 Gulden an das AugustinerChorherrenstift St. Afra ${ }^{50}$, behielt aber die verkaufte Nickel Mönch das Dorf und Vorwerk
Jahnaischer Hof in Meißen Foto: Matthias Donath

30 HStA Dresden, 10024, Geheimer Rat (Geheimes Archiv), Loc. $7997 / 2$. Bl. 51r, vgl. Wiegand 2016, S. 119.

31 CDS II, 4. Nr. 283.

32 Vgl. HStA Dresden, 10004 , Kopiale, Nr. 45, Bl. 236v, vgl. Wiegand 2016, S. 119.

33 Ernst Gotthelf Gersdorf (Hrsg.): Urkundenbuch des Hochstifts Meißen Bd. 3 (Codex diplomaticus Saxoniae regiae II, 3), Leipzig 1865 (folgend CDS II, 3), Nr. 1134, 1207; CDS II, 4, Nr. 480.

34 Vgl. Wiegand 2016.

35 Wiegand 2016, S. 106-120, hier S. 119.

36 Alle erhaltenen Lehnbriefe in HStA Dresden, 10080, Lehnhof Dresden, Nr. O 3119.

37 CDS II, 4, Nr. 325, vgl. auch Reinhard Butz: Artikel „Mühlberg“, in: Heinz-Dieter Heimann (Hrsg.): Brandenburgisches Klosterbuch. Handbuch der Klöster, Stifte und Kommenden bis zur Mitte des 16. Jahrhunderts. Berlin 2007, Bd. 2, S. 894. Vorgänger war Matthäus Mönch, vielleicht ein Verwandter.

38 CDS II, 3, Nr. 1363, 1383 , 1390; 4, Nr. 336, 338, 343 Heinrich Mönch starb nach 1528.

39 CDS II, 4, Nr. 338

40 CDS II, 4, Nr. 325, vgl. Mütze 2016, S. 290.

41 HStA Dresden, 10040, Obersteuerkollegium, Nr. 290, Bl. 115 (Landsteuer 1509); Nr. 293, Bl. 45-46 und Nr. 299, Bl. 49-50 (Türkensteuer 1529); Nr. 297, Bl. 8, 20 (Zinsregister des Augustiner-Chorherrenstifts St. Afra 1529), Nr. 327, Bl. 109 und 328/2, Bl. 421 (Türkensteuer 1547), Nr. 345, Bl. 115 119 (Landsteuer 1551).

42 Landesarchiv Sachsen-Anhalt, Standort Wernigerode (folgend LASA Wernigerode), H 71, Gutsarchiv Frankleben, Nr. 172.

43 HStA Dresden, 10424, Grundherrschaft Niederjahna, Nr. 77.

44 Vgl. Heinz Pannach: Das Amt Meißen vom Anfang des 14. bis zur Mitte des 16. Jahrhunderts. Studien zur Sozialstruktur, Verfassung und Verwaltung. Berlin 1960, S. 151. 


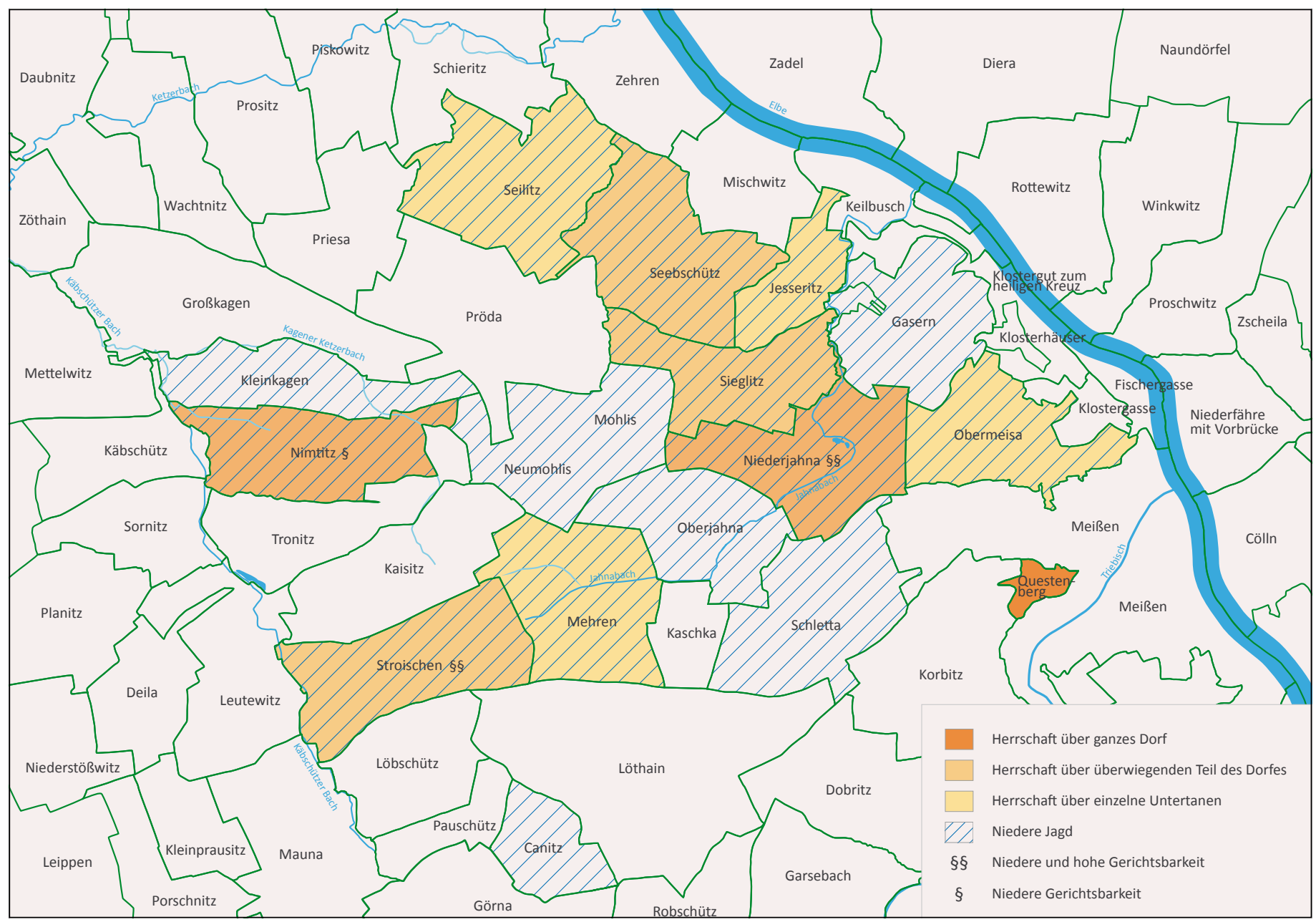

Herrschaftsrechte des Ritterguts Jahna vom 17. bis zum 19. Jahrhundert Kartografie: Alexander Karthe nach Vorlage von Matthias Donath

45 Ein falscher Eintrag im „His torischen Ortsverzeichnis von Sachsen" hat hier Verwirrung gestiftet. In Karlheinz Blaschke: Historisches Ortsverzeichnis von Sachsen. Leipzig 1957, S. 75-76 wird zu Niederjahna aufgeführt: „1551: 5 bes. M. [= besessene Mann, Bauern], 5 Inw. [= Inwohner]“. Pannach 1960, S. 142 und Blaschke/ Baudisch 2006, S. 345 wiederholten diese falsche Angabe. Blaschke entnahm die Angabe der Karteikarten-
Pflicht, für Korbitz ein Ritterpferd zu stellen. Mit dem Lehnbrief vom 10. September 1554 hob Kurfürst August von Sachsen die Ritterdienste für Korbitz auf. Nach Auflösung des Stifts St. Afra kaufte 1543 Ernst von Miltitz auf Batzdorf das Dorf und Vorwerk Korbitz und das Dorf Dobritz, um es seiner neu geschaffenen Herrschaft Siebeneichen anzugliedern. Ein kleiner Anteil von Korbitz gelangte wieder an das Rittergut Jahna. Bis 1841 zinste ein Gartennahrungsbesitzer in Korbitz an das Rittergut Jahna. Stroischen: Aus dem Lehnbrief von 1526 geht hervor, dass Nickel Mönch einen Anteil des Dorfes Stroischen von den Brüdern Antonius und Dietrich von Schönberg auf Rothschönberg samt der niederen Gerichtsbarkeit erworben hat. Da Stroischen im Landsteuerregister von 1509 bereits Nickel Mönch auf Niederjahna zugeordnet ist, muss der Kauf zwischen 1501 und 1509 erfolgt sein. Denkbar ist, dass dazu der Erlös aus dem Verkauf von Korbitz genutzt wurde, was einen Erwerb um 1504/05 nahelegen könnte. Zum Rittergut Jahna gehörten 1526 drei Stroischener Bauern, 1547 erfasste man zwei Bauern, während der Lehnbrief von 1554 von vier Bauern spricht. Die anderen Einwohner in
Stroischen unterstanden dem Amt Meißen. Am 10. September 1554 verlieh Kurfürst August von Sachsen Heinrich Mönch die niedere und obere Gerichtsbarkeit über Stroischen. Das Erbregister von 1693 listet vier Bauern und einen Gärtner auf, und noch 1841 waren es fünf Höfe, die dem Rittergut Jahna unterstanden.

Mehren: Zwischen 1501 und 1509 kaufte Nickel Mönch von den Brüdern Antonius und Dietrich von Schönberg nicht nur drei Bauern in Stroischen, sondern auch einen Bauern in Mehren. 1547 war mindestens einer der fünf Bauern dem Rittergut Jahna zugeordnet. 1611 gehörten 2 Bauern und 2 Gärtner in Mehren, mithin die Hälfte des Dorfes, zum Rittergut Jahna. Demnach muss sich im späten 16. oder frühen 17. Jahrhundert eine Besitzerweiterung vollzogen haben. Die andere Hälfte von Mehren gehörte zum Schulamt Meißen. Aufgrund von Besitzzusammenlegungen gab es im 19. Jahrhundert nur noch zwei Bauerngüter, die dem Rittergut Jahna unterstanden. Beide waren sie 1841 in der Hand eines Besitzers.

Kaschka: Zeitweise muss das Dorf Kaschka, das südlich an Oberjahna angrenzt, zum Rittergut Jahna gehört haben. Die Steuerregister von 
1547 und 1551 führen vier Bauern in Kaschka als Untertanen des Heinrich Mönch zu Jahna auf. Nach der Mitte des 16. Jahrhunderts gehörte Kaschka zum Kreisamt Meißen.

Sieglitz: In den Lehnbriefen des 15. und 16. Jahrhunderts wird Sieglitz nicht erwähnt. 1547 unterstanden die fünf Grundeigentümer Christoph und Michael von Schleinitz. Anders sah es 1611 aus, als 4 Bauern, 2 Gärtner und ein Häusler zum Rittergut Jahna gehörten. Da Sieglitz zuvor zum Rittergut Schieritz gehört hatte, lässt sich erschließen, dass Heinrich von Schleinitz auf Schieritz, der 1579 das Rittergut Jahna kaufte, dieses Dorf von Schieritz nach Niederjahna umgliederte. 1841 gab es in Sieglitz vier Bauernhöfe unterschiedlicher Größe, 2 Gärtner und 2 Häusler.

Seebschütz: Seebschütz unterstand 1547 Hans von Schleinitz auf Ragewitz und 1551 dem Rittergut Schieritz. Danach muss eine Umgliederung zum Rittergut Jahna erfolgt sein, denn 1611 gehörten 4 Bauern, 2 Gärtner und 1 Häusler in Seebschütz zu Jahna und nicht mehr zu Schieritz. 1841 lösten drei Bauern, von denen einer zwei Bauernhöfe in Besitz hatte, sowie zwei Gärtner ihre Dienstpflichten ab.

Jesseritz: Nach dem Amtserbbuch von 1547 unterstanden alle fünf Bauern dem Domkapitel zu Meißen, während das Türkensteuerregister aus dem gleichen Jahr mehrere Einwohner von Jesseritz dem Rittergutsbesitzer Heinrich Mönch zu Jahna zuordnete. In den älteren Steuerregistern und Lehnbriefen wird Jesseritz nicht genannt. Demzufolge müssen um 1547 Einkünfte aus Jesseritz an das Rittergut Jahna übergegangen sein. 1611 bezog das Rittergut Jahna Zinsen aus Jesseritz. Aus dem Ablösungsrezess von 1841 geht hervor, dass ein Halbhufengut dem Rittergut Jahna unterstand.

Seilitz: Seilitz war im Amtserbbuch von 1547 dem Christoph von Schleinitz auf Grödel zugordnet. Ein Steuerregister aus dem gleichen Jahr nennt erstmals Untertanen in Seilitz, die zum Rittergut Jahna gehörten. Demzufolge muss es um 1547 eine Umgliederung von Einkünften gegeben haben. 1611 sind Zinsen für das Rittergut Jahna bezeugt. Im Ablösungsrezess von 1841 sind zwei Höfe aufgeführt, die dem Rittergut Jahna unterstanden, einer mit 2 1/4 Hufen und ein Halbhufengut.

Obermeisa: Im Amtserbbuch von 1547 sind zwölf Hauswirte erfasst, die dem Amt Meißen unterstanden. 1841 gehörte ein Freihof in Obermeisa zum Herrschaftsbezirk des Ritterguts Jahna. Er scheint erst vergleichsweise spät angegliedert worden zu sein.

Zitzschewig: Die Weinberge in Zitzschewig (heute Ortsteil von Radebeul) stammten ver- mutlich aus dem Besitz der Familie Kundige, die seit mindestens 1406 bis um 1420 auf Jahna saß. 1420 kaufte die Stadt Dresden Zinsen von einem Weinberg. ${ }^{51}$ Als 1437 Conrad Mönch mit dem Rittersitz Jahna belehnt wurde, waren auch zwei Weingärten in Kötzschenbroda inbegriffen. Gemeint waren damit Weinberge in der Gemarkung Zitzschewig, die im 15. Jahrhundert nach und nach verkauft wurden. Aus einer Urkunde des Jahres 1476 geht hervor, dass Meißner Dompropst Dietrich von Schönberg einen Weinberg, genannt „der große Seidenberg“, von Conrad Mönch erworben hatte. ${ }^{52}$ Aus dem Nachlass einer Frau Nitzsche in Oberjahna stiftete der Rat der Stadt Meißen einen Altar der heiligen Fabian und Sebastian in der Meißner Frauenkirche. Dazu erwarb man von Conrad Mönch 1476 den halben Weinberg, genannt „der Wahnsdorf“. ${ }^{53}$ Im Lehnbrief von 1486 werden noch „etliche Weinberge“ in „Zcuschkewicz" genannt. Bis zur Mitte des 16. Jahrhunderts gingen sämtliche Besitzteile in Zitzschewig verloren, so dass dieser Ort nicht mehr in den Lehnbriefen aufgeführt wurde. Letztmals werden Untertanen in Zitzschewig im Türkensteuerregister von 1547 genannt.

Niederhermsdorf: Niederhermsdorf (heute ein Ortsteil von Freital) liegt abseits von dem Besitzkomplex nahe Meißen, und es erscheint unklar, wie die Familie Mönch zu diesem Besitz im Amt Dresden gelangte. 1486 jedenfalls empfingen die Brüder Mönch das „halbe Dorff Hermerstorff mit Erbgerichten“ zu Lehen. ${ }^{54}$ Auch in weiteren Lehnbriefen des 16. Jahrhunderts wird dieser Ort genannt. In den Steuerregistern der Jahre 1509 und 1529 erscheint er nicht, dafür in den Verzeichnissen von 1547 und 1551. Im späten 16. oder frühen 17. Jahrhundert ging der Besitz im Amt Dresden verloren. Zu vermuten ist, dass diese entfernt liegenden Herrschaftsteile verkauft wurden, um Anteile von Sieglitz, Seebschütz und Mehren bei Niederjahna zu erwerben.

Kohlsdorf: Mit Niederhermsdorf war auch der Nachbarort Kohlsdorf verbunden. Allerdings wird dieser Ort in der Lehnsurkunde von 1486 nicht genannt. Dafür erscheint er 1486 in einem Verzeichnis der Amtsassen des Amtes Dresden als Besitz des Conrad Mönch. ${ }^{55}$ In den Steuerregistern fehlt Kohlsdorf. Im Lehnbrief vom 7. September 1579 für Hans von Schleinitz wird Kohlsdorf ausdrücklich aufgeführt. Der Ort erscheint noch im Lehnbrief von 1586, dann aber nicht mehr, was auf einen Verkauf dieses Besitzes hindeutet.

Wurgwitz: Zwischen Niederhermsdorf und Kohlsdorf liegt Wurgwitz, das ebenfalls zum Besitzkomplex der Familie Mönch südlich von sammlung für das Historische Ortsverzeichnis, Amtshauptmannschaft Meißen, jüngere Serie (HStA Dresden, 19010, Spezialinventar Historisches Ortsverzeichnis), wo auf das Landsteuerregister $1551 \quad$ (HStA Dresden, 10040, Obersteuerkollegium, Nr. 345) verwiesen wird. Dort sind allerdings nicht fünf Bauern eingetragen, sondern fünf Bewohner, die gemäß dem dort verzeichneten Vermögen eindeutig als Gärtner identifiziert werden können. Im Türkensteuerregister von 1547 sind für Niederjahna fünf Gärtner eingetragen und mit Namen vermerkt (HStA Dresden, 10040, Obersteuerkollegium, Nr. $328 / 2$, Bl. 421). Auch die anderen Steuerregister nennen nur Gärtner, aber nie Bauern. Alle ausgewerteten Dokumente belegen, dass es in Niederjahna nie Bauern oder besessene Mann gab, dafür aber Gärtner und Häusler.

46 Die Zahlen zu 1693 und 1759 sind der Zettelkartei in HStA Dresden, 19010, Spezialinventar Historisches Ortsverzeichnis, ältere Serie entnommen, wo sich auch genaue Nachweise befinden. Die Zahlen zu 1611 und 1847 sind oben nachgewiesen.

47 Zur Grundstücksgeschichte vgl. ausführlich Wilhelm Loose: Die Topographie der Stadt Meißen. In: Mitteilungen des Vereins für $\mathrm{Ge}$ schichte der Stadt Meißen 3 (1894), S. 122-125. Der Verkauf 1565 bezieht sich laut den Lehnsakten auf den Maltitzer Hof, nicht auf den Schleinitzer Hof.

48 Cornelius Gurlitt: Beschreibende Darstellung der älteren Bau- und Kunstdenkmäler des Königreichs Sachsen. Bd. 39. Meißen (Stadt, Vorstädte, Afrafreiheit und Wasserburg). Dresden 1917, S. 433-437.

49 CDS II, 4, Nr. 482.

50 CDS II, 4, Nr. 325-326, vgl. auch HStA Dresden, 10080 , Lehnhof Dresden, U 32.

51 CDS II, 5, Nr. 164.

52 CDS II, 3, Nr. 1195.

53 CDS II, 4, Nr. 134.

54 HStA Dresden, 10080, Lehnhof Dresden, Nr. O 3119.

55 HStA Dresden, 10024, Geheimer Rat (Geheimes Archiv), Loc. $7997 / 4$, Bl. 4r, vgl. Wiegand 2016, S. 119. 
Steuerregister zur Erhebung der Türkensteuer 1529 aus dem Rittergut Jahna. Links stehen die Einwohner in Nimtitz, rechts die in Stroischen, Niederjahna und Questenberg. Es ist die älteste namentliche Auflistung der Bewohner. ○ Sächsisches Staatsarchiv, Hauptstaatsarchiv Dresden

\section{Ebenda.}

57 Vgl. Ahnenreihenwerk Gebrüder Fischer. Bd. 4. Ahnenreihen von Uradelsgeschlechtern Wettiner Lande. Teil 4. Rüningen 1967, Genealogie der Familie von Schleinitz, S. 8-10.

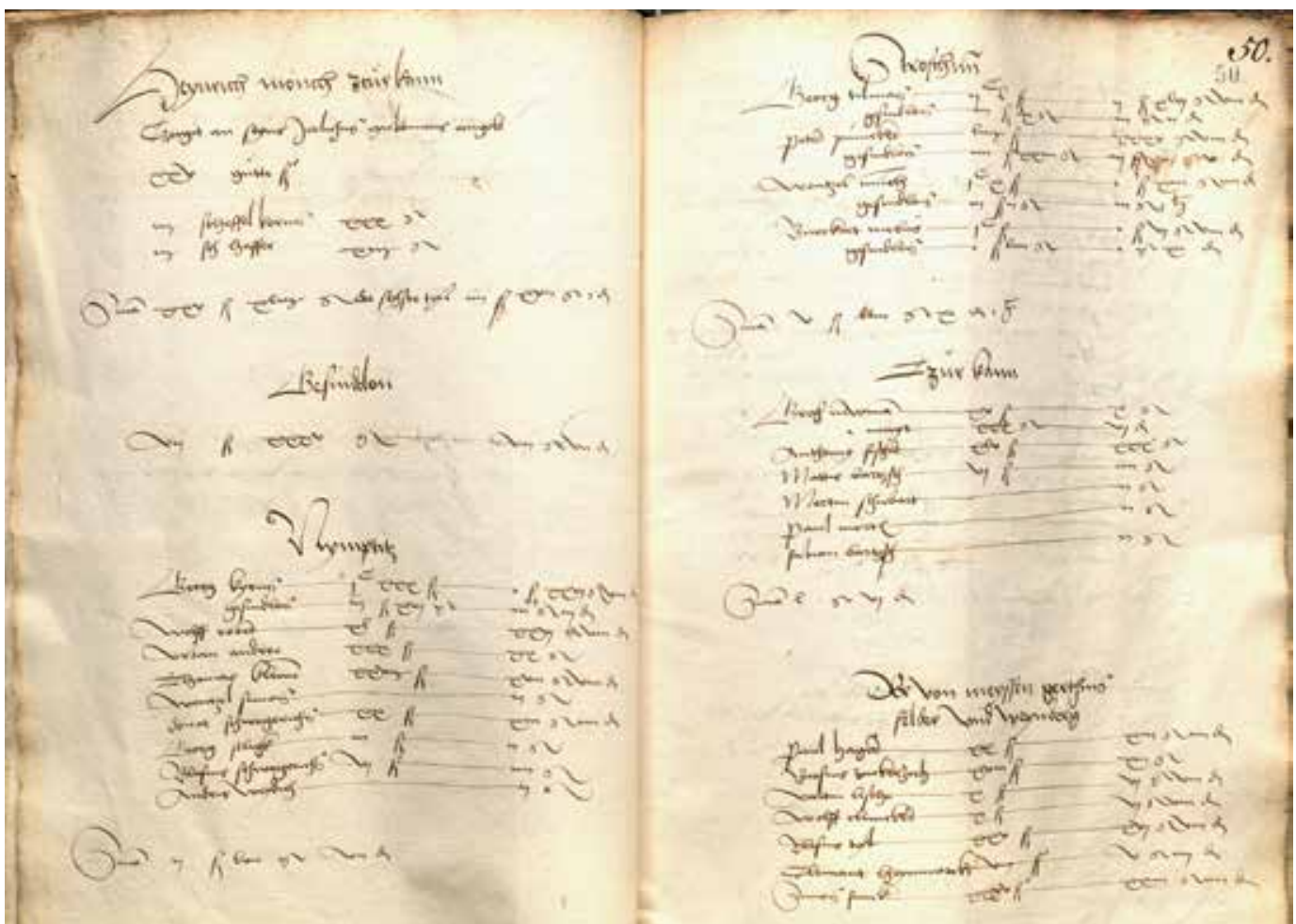

Dresden gehörte. In den Lehnsurkunden wird der Ort allerdings nie namentlich genannt. Dafür ist er 1486 in einer Liste der Amtssassen des Amtes Dresden eingetragen. ${ }^{56}$ Außerdem führen die Steuerregister der Jahre 1547 und 1551 Wurgwitz unter den Besitzungen des Heinrich Mönch auf. Niederhermsdorf, Kohlsdorf und Wurgwitz wechselten wohl Ende des 16. Jahrhunderts den Besitzer, so dass die Verbindung mit Niederjahna erlosch.

$\mathrm{Zu}$ Beginn des 17. Jahrhunderts umfasste das Rittergut Jahna somit ein ganzes Dorf (Niederjahna), größere Anteile von fünf Dörfern (Nimtitz, Stroischen, Seebschütz, Sieglitz, Mehren), eine Häuslersiedlung (Questenberg) und einzelne Höfe in vier Dörfern (Jesseritz, Korbitz, Oberjahna, Seilitz). Diese Orte lagen nahe beieinander, bildeten aber keinen geschlossenen Herrschaftsbezirk. Mit Ausnahme von Niederjahna und Stroischen, wo das Rittergut auch die obere Gerichtsbarkeit (Obergericht) innehatte, konnte es in den Dörfern nur die niedere Gerichtsbarkeit (Erbgericht) ausüben. Das Recht der niederen Jagd stand dem Rittergut Jahna 1611 nicht nur im genannten Herrschaftsbezirk $\mathrm{zu}$, sondern auch in den Amtsdörfern Obermeisa, Oberjahna, Mohlis, Canitz, Kleinkagen und Gasern. Auch die Fluren des Ritterguts Schletta durften von Niederjahna aus bejagt werden. Jahna war ursprünglich ein amtsässiges Rittergut im Amt Meißen. Hans von Schleinitz erwirkte, dass Kurfürst August von Sachsen 1583 die Schriftsässigkeit zugestand, was Kurfürst dem waren die Rittergutsbesitzer berechtigt, an den kursächsischen Landtagen teilzunehmen. Das Rittergut Jahna war mit zwei Ritterpferden belastet. Das bedeutet, dass im Kriegsfall zwei bewaffnete Reiter mit Pferden und Knechten zu stellen waren. Seit dem 16. Jahrhundert wurde der Ritterdienst durch Zahlungen abgegolten.

\section{Die Familie von Schleinitz in Niederjahna}

Hans von Schleinitz (1540-1613) auf Schieritz gehörte jenem weitverzweigten Geschlecht an, das sich nach dem Stammsitz Schleinitz in der Lommatzscher Pflege nannte und umfangreichen Grundbesitz links und rechts der Elbe erwerben konnte. Er war der Sohn des Georg von Schleinitz (1512-1555) auf Schieritz und Seerhausen und der Katharina von Karras (gest. vor 1548). ${ }^{57}$ Er erbte das Rittergut Schieritz und begründete damit den Zweig Schieritz-Jahna-Jahnishausen-Putzkau, während sein Bruder Georg (1547-1592), dem das Rittergut Seerhausen zufiel, einen eigenen Zweig hervorbrachte. Hans von Schleinitz heiratete 1565 Maria von Sundhausen (1545-1613). Aus der Ehe gingen zwölf Kinder hervor, von denen die meisten früh starben. Der 1579 vollzogene Erwerb des Ritterguts Jahna bedeutet eine Erweiterung seines Herrschaftskomplexes nach Südosten. Obwohl er mit dem Schloss Schieritz bereits ein stattliches Renaissanceschloss besaß, ließ er in Niederjahna ein neues Herrenhaus in Renais-
Christian II. 1613 noch einmal bestätigte. Seit- 
sanceformen erbauen. Das Mauerwerk des heutigen Gebäudes stammt noch aus dieser Bauphase um 1580. Erhalten blieb auch das Renaissance-Rundbogenportal mit den Wappen der Familien Schleinitz und von Sundhausen in den Zwickeln. 1610/11 ließ Hans von Schleinitz den Jahnaischen Hof in Meißen neu errichten.

Nachdem Hans von Schleinitz am 8. Februar 1613 verstorben war, losten die drei überlebenden Söhne um den Besitz. Dabei fiel Jahna an Heinrich von Schleinitz (1573-1654), der in erster Ehe mit Agnes Pflug, in zweiter Ehe mit Elisabeth von Holtzendorff (1591-1640) und in dritter Ehe mit Dorothea von der Pfordte (1621-1656) vermählt war. Alle drei Ehen blieben kinderlos. Er und seine zweite und dritte Frau sind als lebensgroße Holzfiguren auf einem Epitaph in der St. Afrakirche in Meißen dargestellt, das um 1656 von Valentin Otte geschaffen wurde. Heinrich von Schleinitz war über dreißig Jahre im Kriegsdienst. Bei dem Einfall der Schweden 1637 geriet er in Gefangenschaft, zudem wurden die Dörfer des Amtes Meißen von den Schweden verwüstet und ausgeplündert, so dass er mehrfach Schulden aufnehmen musste. Es reichte nicht, dass die zwei- te und die dritte Ehefrau ein bedeutendes Ehegeld eingebracht hatten. Die verwitwete dritte Frau konnte trotz der Zusicherung der Ehestiftung kaum Erträge aus dem Rittergut Jahna entnehmen. Bereits 1656 verstarb sie. Unterdessen war das Rittergut Jahna an die Neffen des Heinrich von Schleinitz gefallen, die Söhne seines Bruders Christoph von Schleinitz (1576-1651) auf Putzkau und Schieritz. Diese mussten Teile des Besitzes verkaufen, um die Gläubiger zu bedienen, darunter das zugefallene Rittergut Bornitz. Das Rittergut Putzkau geriet in Konkurs, und so verlor auch die Mutter der beiden, Katharina von Schönberg, ihr eingebrachtes Vermögen. Ihre Witwenversorgung musste auf das Gut Jahna übertragen werden. 1657 drängten die Gläubiger die beiden Brüder, die Güter Jahna und Schieritz für 2.000 Taler zu verpfänden. 1662 vereinbarten die Brüder eine Besitzteilung. Der jüngere Joachim Heinrich von Schleinitz (1627-1678) wählte Jahna, den kleineren Anteil, während Hans Christoph von Schleinitz (1625-1679) Schieritz erhielt, dafür aber auch die Schuldenlast tragen musste.

Joachim Heinrich von Schleinitz heiratete 1662 Ursula Perpetua Pflug (1640-1709), das älteste Kind des Otto Heinrich Pflug (1615-1670) auf
Genealogische Übersicht der Besitzer des Ritterguts Jahna (fett) bzw. der Inhaber des Fideikommisses (gelb unterlegt) ๑ Grafische Darstellung von Alexander Karthe nach Entwurf von Matthias Donath

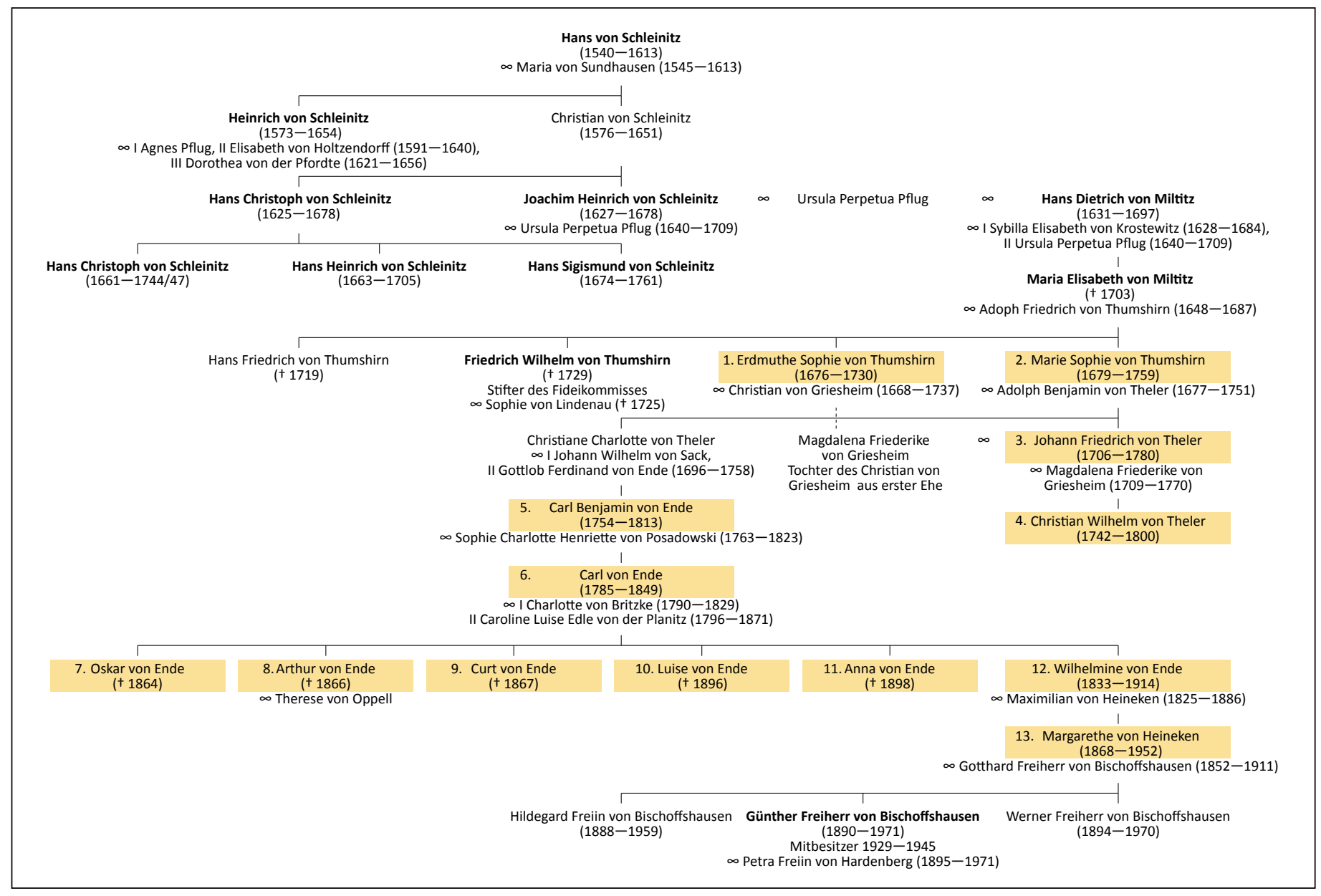


58 Zur Familie von Miltitz in Sachsen vgl. Hausen 1892, S. 434-436; Heinrich Erwin Ferdinand von Feilitzsch: Zur Familiengeschichte des Deutschen, insonderheit des Meissnischen Adels von 1570 bis ca. 1820. Großenhain/ Leipzig 1896, S. 188-195; Walter von Hueck: Adelslexikon. Bd. IX. Limburg an der Lahn 1998, S. 76-77.

59 HStA Dresden, 10057, Kreisamt Meißen, Nr. 1675.

60 HStA Dresden, 10057, Kreisamt Meißen, Nr. 1674.

61 Der Kaufvertrag ist überliefert in LASA Wernigerode, H 71, Gutsarchiv Frankleben, Nr. 172

62 Dieser zweite Kaufvertrag von 1689 ist nicht erhalten.

Epitaph für Heinrich von Schleinitz und zwei seiner Ehefrauen in der St. Afrakirche in Meißen, nach 1654

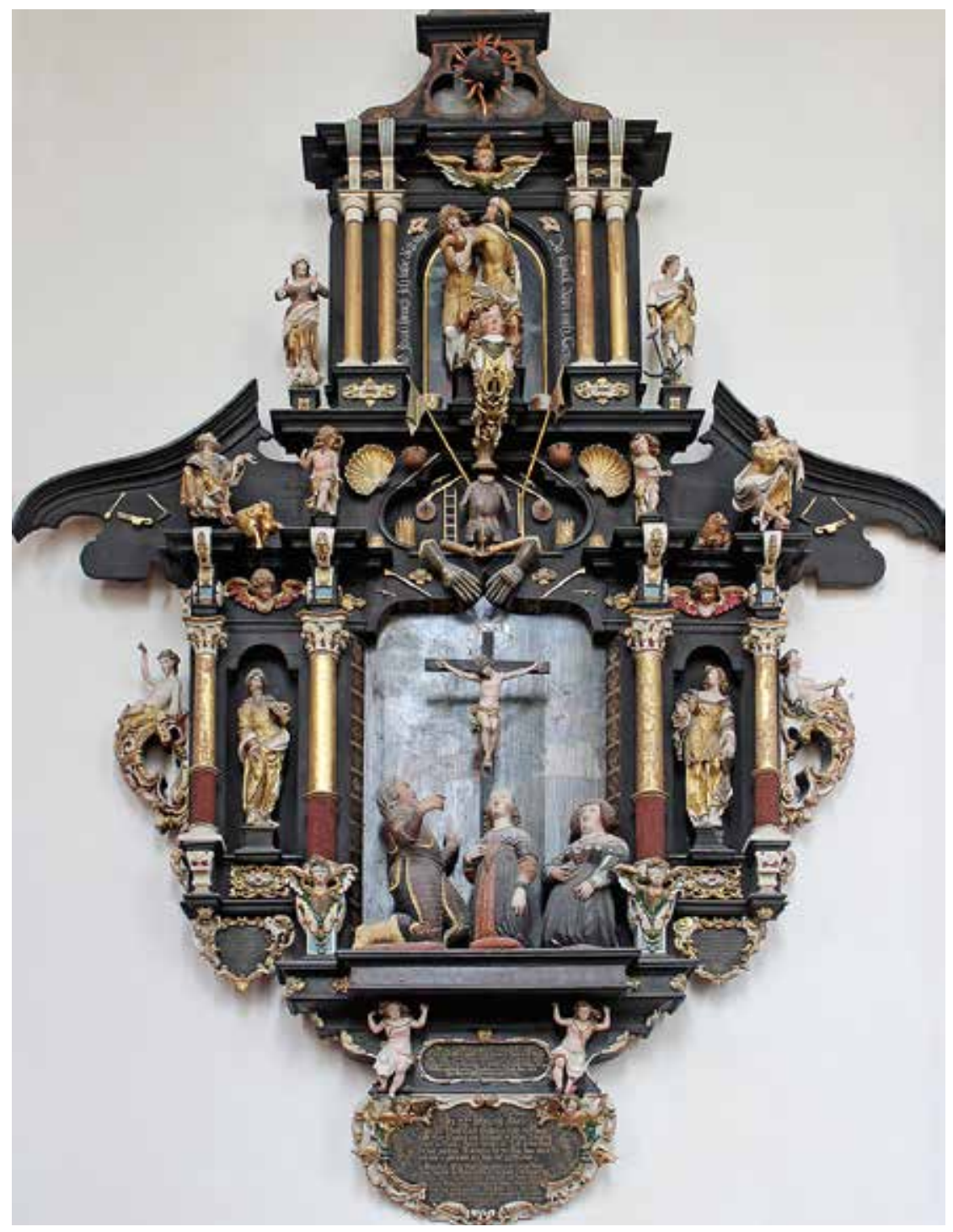

nem Verkauf bereit. Am 3. Juni 1686 baten sie Kurfürst Johann Georg III. als ihren Lehnsherrn um die Erlaubnis, das Rittergut Jahna verkaufen zu dürfen, während sie am 15 . Juni 1686 mit Hans Dietrich von Miltitz einen Kaufvertrag schlossen. ${ }^{59}$ Der Verkaufspreis sollte 18.000 Gulden und 400 Taler betragen. Da Miltitz sowohl die auf dem Gut lastenden Schulden als auch die Eheverschreibung für Ursula Perpetua Pflug übernahm, hätte er bei der Übergabe an die Verkäufer nur 7.000 Gulden zahlen müssen. 3.000 Gulden waren einen Schuldner auszuhändigen. Obwohl bereits eine konkrete Einigung vorlag, ordnete das Kreisamt Meißen am 6. August 1686 eine Zwangsversteigerung (Subhastation) an. ${ }^{60}$ Umgehend bot Hans Dietrich von Miltitz den Kaufpreis von 18.000 Gulden und 400 Taler. ${ }^{61}$ Obwohl nochmals eine Angebotsfrist von sechs Wochen ausgeschrieben wurde, ging kein höheres Angebot ein. Doch der Kaufvertrag wurde nicht wirksam, weil Hans Georg von Schleinitz (1621-1688) auf Graupzig, Gödelitz, Seerhausen und Zschochau am 13. Oktober 1686 Einspruch erhob. Als Mitbelehnter forderte er aufgrund des „Nähergeltungs-Rechts“ ein Vorkaufsrecht, was ihm der Kurfürst auch zubilligte. So musste Hans Dietrich von Miltitz am 14. Mai 1687 wieder auf das fast schon gewonnene Rittergut Jahna verzichten. Ein Druckmittel blieb jedoch das Ehegeld seiner zweiten Frau, das auf Jahna lastete. Am 14. Januar 1688 starb Hans Georg von Schleinitz, ohne männliche Lehnserben zu hinterlassen. Seine Witwe Rahel Sophie von Schleinitz, geborene von Friesen, zahlte die Ansprüche der Ursula Perpetua von Miltitz, die noch auf Jahna lasteten, aus, insgesamt 3.400 Gulden. Und nun willigte auch Andreas Dietrich III. von Schleinitz (1646-1703) auf Mautitz und Canitz als Vormund des noch minderjährigen Hans Sigismund von Schleinitz in einen Verkauf des Ritterguts Jahna ein, und so kaufte Hans Dietrich von Miltitz das Rittergut Jahna 1689 ein zweites Mal. ${ }^{62}$

Sogleich ging er daran, diesen Besitz seinen Nachkommen zu sichern. Er hatte acht Kinder erster Ehe, von denen aber schon mehrere verstorben waren. Der Sohn Hans Dietrich kämpfte als kursächsischer Offizier in Griechenland gegen die Türken, denn Kurfürst Johann Georg III. hatte drei sächsische Regimenter an die Republik Venedig „vermietet“. Seine Rückkehr war unsicher. Hans Dietrich von Miltitz wusste nicht, dass er bereits 1685 auf Morea (Peleponnes) ums Leben gekommen war. Ohne männlichen Erben war zu erwarten, dass das Rittergut Siebeneichen wie auch das mühsam erworbene Jahna an männliche Seitenverwandte 
fielen. Um aber seine Töchter abzusichern, bat er den Kurfürsten am 22. März 1689, „das Mann Lehn an gedachtem Guthe Jahna in Erblehn zuverwandeln“. ${ }^{63}$ Noch am gleichen Tag wies Johann Georg III., der gerade in Karlsbad weilte, seine Räte an, dieser Bitte nachzukommen, und so wurde mit Urkunde vom 29. Mai 1689 das Lehen in einen freien Besitz umgewandelt. Das bedeutete, dass Jahna weiterhin ein schriftsässiges Rittergut blieb, aber nicht mehr dem Lehnsrecht unterlag. Der Besitz durfte frei vererbt werden, auch an weibliche Nachkommen. Dagegen blieb das Rittergut Siebeneichen ein Lehen.

\section{Hans Dietrich von Miltitz und das Fideikommiss Jahna}

Hans Dietrich von Miltitz ${ }^{64}$ und seine Frau Ursula Perpetua veranlassten nach dem Erwerb eine umfassende Modernisierung des Herrenhauses. So erhielt der Herrensitz um 1690 die noch heute sichtbare Gestalt.

Hans Dietrich von Miltitz konnte sein Anwesen nur wenige Jahre nutzen. Er starb am 4. Januar 1697 im Alter von 65 Jahren. Neben seiner Witwe hinterließ er zwei erwachsene Töchter, während die anderen Kinder bereits gestorben waren. Maria Elisabeth von Miltitz (gest. 1703) hatte Adolph Friedrich von Thumshirn (16481687) geehelicht, der jedoch nicht mehr am Leben war. Aus dieser Ehe stammten die Söhne Hans Friedrich (gest. 1719) und Friedrich Wilhelm (gest. 1729) sowie die Töchter Erdmuthe Sophie (1676-1730) und Marie Sophie (16791759). Außerdem lebte noch die Tochter Esther Elisabeth, die in erster Ehe mit Moritz Albrecht von Hartitzsch auf Krummenhennersdorf und in zweiter Ehe mit Julius Haubold von Hartitzsch verheiratet war. Die Rittergüter Siebeneichen und Korbitz fielen gemäß Lehnsrecht an den nächstverwandten männlichen Lehnserben, den Neffen Johann Gebhard von Miltitz (1682-1703). Die Nachfolge in Jahna hatte der Verstorbene genau geregelt. Da er den Wunsch hatte, dass ein Mann den Besitz führen sollte, hatte er in seinem Testament vom 14. September 1695 bestimmt, es möge einer der beiden Söhne seiner Tochter Maria Elisabeth zur Nachfolge gelangen. ${ }^{65}$

Doch die beiden Töchter fühlten sich übergangen. Esther Elisabeth interpretierte den letzten Willen ihres Vaters so, dass ihre Neffen erst nachfolgen sollten, wenn sie und ihre Schwester gestorben waren. Am 1. September 1697 einigten sich beide Schwestern auf einen Vergleich. Esther Elisabeth verzichtete zugunsten ihrer älteren Schwester und ihrer Neffen auf Jahna, erhielt aber dafür einen umfangreichen Anteil am

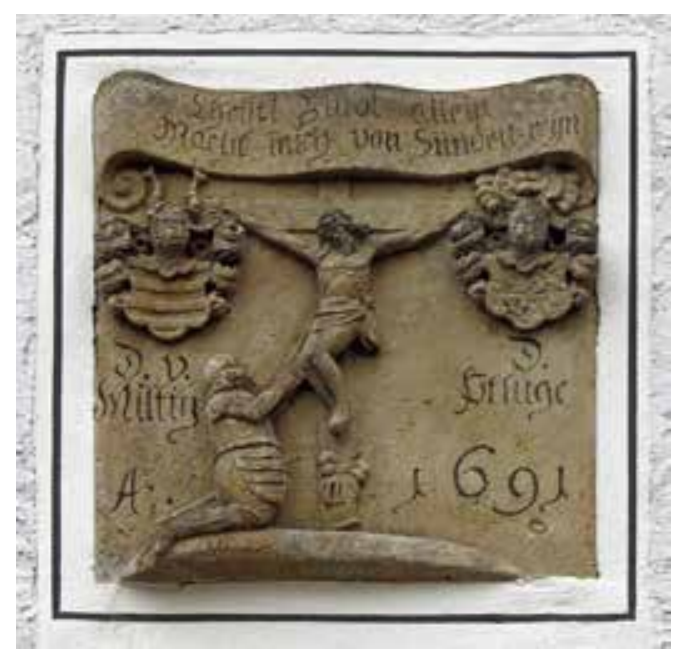

Sandsteinrelief über dem Portal des Herrenhauses Niederjahna mit dem vor dem Kruzifix knienden Hans Dietrich von Miltitz, 1691

väterlichen Erbe und am Einkommen des Ritterguts. Ihr wurden 9.225 Gulden ausgezahlt, außerdem bekam sie die Hälfte der Zinsen, die die Untertanen zu entrichten hatten. Maria Elisabeth von Thumshirn, offenbar eine zupackende Frau, überließ das Rittergut zum 1. September 1697 ihren Söhnen Hans Friedrich und Friedrich Wilhelm, behielt aber die Betriebsführung. ${ }^{66}$ Da der ältere Hans Friedrich von Thumshirn in den Hofdienst des Herzogs von Sachsen-Gotha getreten war und wohl kein Interesse an Jahna hatte, trat er seinen Anteil 1702 für 1.500 Gulden seinem jüngeren Bruder Friedrich Wilhelm ab. ${ }^{67}$ Dieser lebte mit seiner Frau Sophie, geborene von Lindenau, in Niederjahna. Da seine Ehe kinderlos blieb, entschloss er sich, ein Fideikommiss zu stiften. Am 17. November 1716 legte er diese Stiftung, die mit seinem Tod wirksam wurde, in seinem letzten Willen nieder. ${ }^{68}$ Demnach sollte das Rittergut Niederjahna mit dem Freihaus in Meißen ungeteilt an seine nächsten Verwandten übergehen. Zunächst sollte seine Ehefrau nachfolgen, dann der ältere Bruder Hans Friedrich und dann die Schwestern. Danach sollte der Besitz als Majorat an den jeweils ältesten männlichen Nachkommen übergehen. Nur wenn keine männlichen Nachkommen vorhanden waren, durften auch weibliche Familienmitglieder nachfolgen.

Als Friedrich Wilhelm 1729 starb, waren mit einer Ausnahme bereits die meisten Verwandten gestorben, die er in der Nachfolgeregelung bedacht hatte: 1719 der Bruder Hans Friedrich, der weder Frau noch Kinder hatte, und 1725 die Ehefrau Sophie. Damit fiel das Fideikommiss zuerst an die älteste Schwester Erdmuthe Sophie von Griesheim, die in zweiter Ehe mit Christian von Griesheim (1668-1737), Geheimer Rat und Konsistorialpräsident im Herzogtum Sachsen-Gotha, verheiratet war. Da ihre beiden Kinder zweiter Ehe bald nach der Geburt verstorben waren, hatte sie keine Nach-
63 HStA Dresden, 10080, Lehnhof Dresden, Nr. O 3123.

$64 \mathrm{Zu}$ ihm vgl. die Leichenpredigt in HStA Dresden, 10570, Grundherrschaft Siebeneichen bei Meißen, Nr. 9.

65 HStA Dresden, 10057, Kreisamt Meißen, Nr. 1168.

66 Ihr Testament ist überliefert in HStA Dresden, 10590 , Grundherrschaft Taubenheim bei Meißen, Nr. 884.

67 HStA Dresden, 10080, Lehnhof Dresden, Nr. O 3121.

68 HStA Dresden, 10080, Lehnhof Dresden, Nr. O 3127. 
Ahnenprobe des Christian Wilhelm von Theler auf Jahna - Sächsisches Staatsarchiv, Hauptstaatsarchiv Dresden kommen. Als sie am 21. April 1730 starb, gelangte das Fideikommiss, das sie gerade erst erlangt hatte, an die jüngere Schwester Marie Sophie, verheiratet mit Adolph Benjamin von Theler (1677-1751) auf Wohla und Niedergersdorf bei Kamenz. Nahezu dreißig Jahre war Marie Sophie von Theler für den Besitz verantwortlich. Da sie drei Söhne hatte, schien es, dass die Nachfolge im Mannesstamm gesichert war. Als sie 1759 starb, hätte nach der Ordnung des Fideikommisses eigentlich die älteste Tochter des ältesten Sohnes Wolf Adolph von Theler (gest. 1756), welcher schon gestorben war, nachfolgen sollen, nämlich Johanna Sophia Friederika von Theler (geb. 1744). Doch noch am Tag, an dem seine Mutter gestorben war, ergriff der zweite Sohn Johann Friedrich von Theler (1706-1780) von dem Rittergut Besitz, der das Majorat als ältester der lebenden Söhne für sich beanspruchte. Dagegen erhob Alexander Christian von Schönberg (1724-1801), der Vormund des Carl Benjamin von Ende (1754-1813), Einspruch. Er forderte die Nachfolge seines Schützlings, des Sohnes der Schwester der Verstorbenen. Carl Benjamin von Ende war das Kind zweiter Ehe der Christiane Charlotte von Ende, geborene von Theler. Der Streit zog sich über zwei Jahre hin. Am 3. Februar 1761 einigten sich die Parteien auf die Nachfolge Johann Friedrich von Thelers, des ältesten aller lebenden Anwärter auf den Fideikommiss, während die Kinder der Schwestern leer ausgingen.

Johann Friedrich von Theler hatte 1730 Magdalene Friederike von Griesheim (1709-1770) geehelicht, die Tochter des Christian von Griesheim, der mit Johann Friedrichs Tante Erdmuthe Sophie von Griesheim, geborene von Thumshirn, verheiratet war. Aus der Ehe gingen zwei Söhne hervor. Johann Friedrich und sein Bruder Carl August von Theler (1712-1768) waren auch Besitzer der Rittergüter Wohla und Niedergersdorf im Markgraftum Oberlausitz, welche sie 1764 verkauften. Als Johann Friedrich von Theler starb, folgte ihm sein ältester Sohn Christian Wilhelm von Theler (1742-1800) als Inhaber des Fideikommisses nach. Er starb am 19. März 1800 unverheiratet und ohne Leibeserben. Auch sein Bruder, der preußische Premierleutnant Carl Alexander von Theler (17441780), war bereits gestorben, ohne Nachkommen zu hinterlassen. Mit beiden Brüdern war die Adelsfamilie von Theler im Mannesstamm erloschen. Damit stellte sich erneut die Frage der Nachfolge.

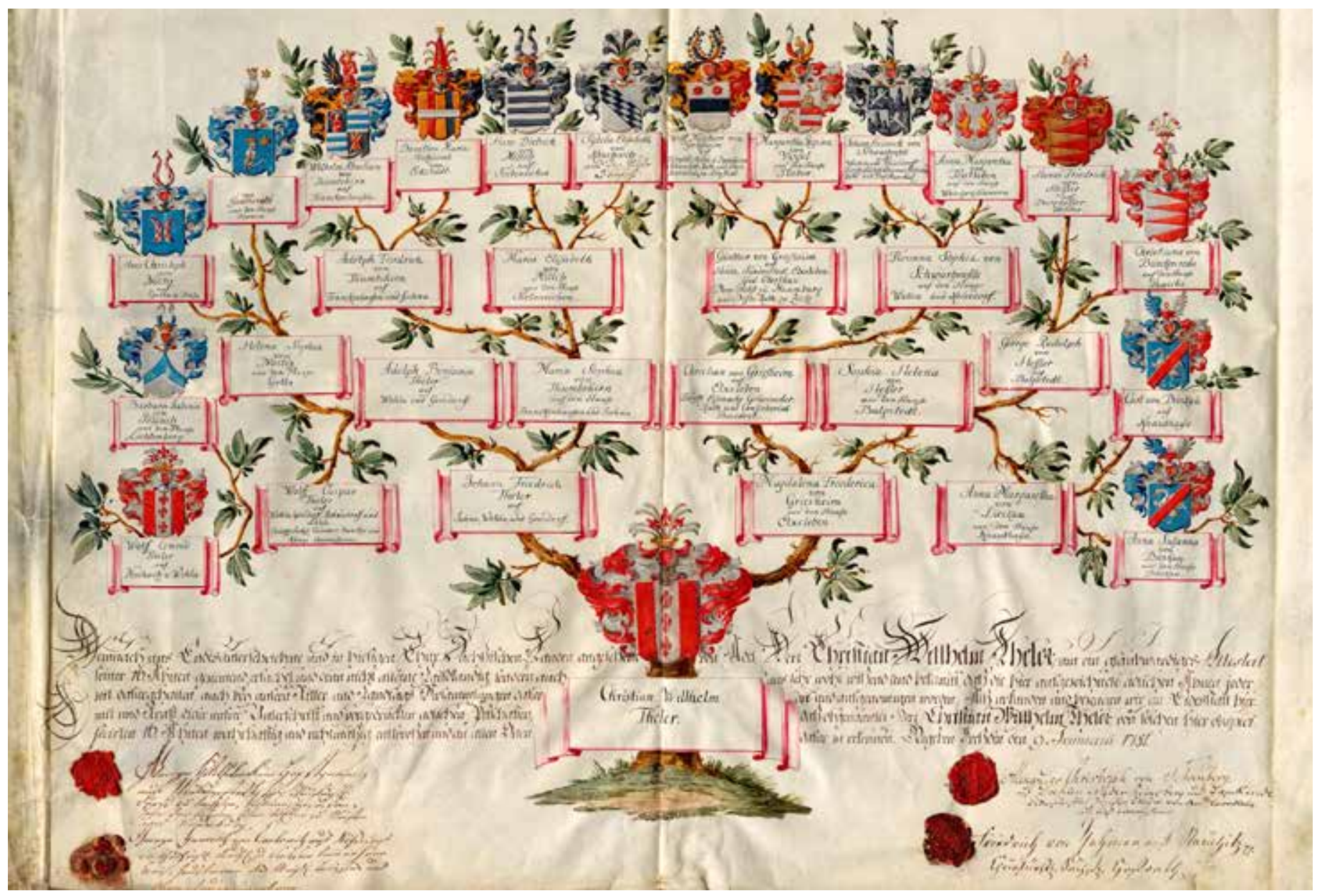




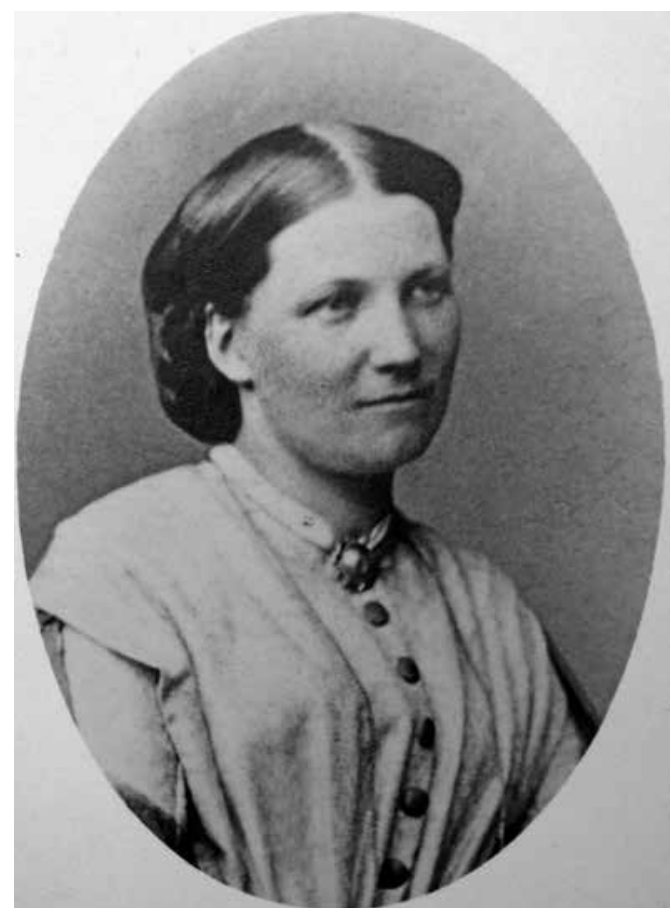

Der letzte noch lebende männliche Nachkomme einer der Schwestern des Fideikommissstifters war Carl Benjamin von Ende. Er war der einzige Sohn des Gottlob Ferdinand von Ende (1696-1758) auf Munzig und Taubenheim und seiner zweiten Ehefrau Christiane Charlotte von Theler, verwitwete von Sack. In männlicher Linie entstammte er dem Seitenzweig Porschnitz-Munzig-Taubenheim der meißnischen Adelsfamilie von Ende. Diese war angeblich schon 1426 in den Freiherrenstand erhoben worden, was Kaiser Karl V. (1500-1558) am 31. Oktober 1530 nochmals bestätigte. Allerdings führten die meisten Zweige der Familie von Ende den Freiherrentitel nicht. Carl Benjamin von Ende hatte das Rittergut Taubenheim geerbt, das seit dem 16. Jahrhundert im Besitz seiner Vorfahren gewesen war. Allerdings hatte sein Vormund 1764 dieses Rittergut verkaufen müssen. Carl Benjamin von Ende hatte in Sachsen kein Einkommen mehr und ging daher nach Schlesien, wo er in den Dienst des Herzogs Friedrich August von Braunschweig-LüneburgOels (1740-1805) trat und als Kammerpräsident im Herzogtum Oels wirkte. Im Alter von 46 Jahren wurde er wieder nach Niederjahna gerufen, denn ihm fiel das Fideikommiss zu. Christian Wilhelm von Theler hatte ihn außerdem zum Universalerben seines Allodialvermögens eingesetzt. ${ }^{69}$ Doch wieder gab es Streit, denn eine Verwandte beanspruchte ebenfalls die Nachfolge. Henriette Benigna von Leipziger, geborene von Scheidt, die Enkelin des Wolf Adolph von Theler, machte geltend, dass sie von einem männlichen Berechtigten abstamme,

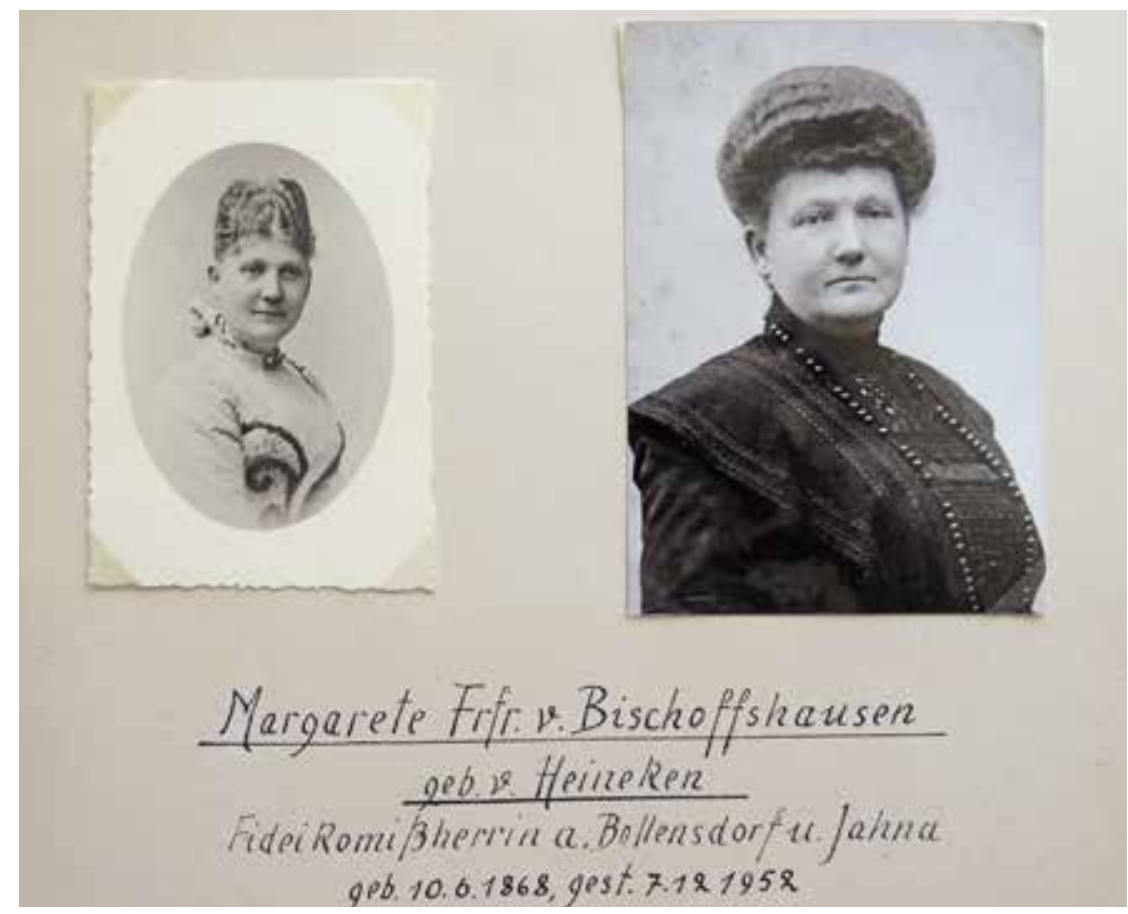

während Carl Benjamin von Ende von einer Schwester ihres Großvaters abstamme. Der Rechtsstreit wurde in letzter Instanz zugunsten von Carl Benjamin von Ende entschieden. Für ihn sprach, dass er männlichen Geschlechts war, denn laut Fideikommissstiftung sollten männliche Abkömmlinge den Vorrang vor weiblichen haben.

Carl Benjamin von Ende starb am 17. November 1813, ein Monat nach der Völkerschlacht bei Leipzig, im Alter von erst 59 Jahren. Aus der Ehe mit Sophie Charlotte Henriette von Posadowsky (1763-1823) hatte er drei Kinder, darunter aber nur einen Sohn. Carl von Ende (1785-1849) führte über 30 Jahre das Rittergut, dessen Wirtschaftsbetrieb verpachtet war. Unter seiner Herrschaft wurde 1841 die Auflösung der Grunddienstbarkeiten vollzogen. Er heiratete in erster Ehe Charlotte von Britzke (1790-1829) und nach deren Tod Caroline Luise Edle von der Planitz (1796-1871). Sechs seiner Kinder wurden nacheinander Inhaber des Fideikommisses. Zunächst übernahm 1849 der älteste Sohn Oskar von Ende, Oberleutnant der sächsischen Armee, das Rittergut Jahna. Er starb am 10. Februar 1864 unverheiratet und ohne Kinder, womit das Fideikommiss an seinen Bruder Arthur gelangte. Dieser nahm als königlich sächsischer Hauptmann am Deutschen Krieg teil und wurde während der Schlacht bei Königgrätz am 3. Juli 1866 in Probluz bei Königgrätz so schwer verwundet, dass er am 22. Juli 1866 seinen Verletzungen erlag. Ein Denkmal auf dem Kirchhof in Probluz erinnert an ihn und die mit ihm gefallenen sächsi-
Links: Wilhelmine von Heineken, geborene von Ende

Rechts: Margarete Freifrau von Bischoffshausen, geborene von Heineken

๑ Archiv ZKG
69 HStA Dresden, 13469, Schulamt Meißen, Nr. 253; 12881, Genealogica, Nr. 5612, Bl. 3340 . 
70 Vgl. Martin Schuster: Carl Heinrich von Heineken (1707-1791) und seine Nachfahren, in: Lars-Arne Dannenberg/Matthias Donath (Hrsg.): Lebensbilder des sächsischen Adels I. Bernstadt a.d. Eigen 2014, S. $83-100$.

71 HStA Dresden, 11025, Oberlandesgericht Dresden, Nr. 4434. Das vorhandene Dokument trägt keinen Datumseintrag. Die Löschung der Anwartschaft erfolgte zum 12. April 1929

Günther Freiherr und Petra Freifrau von Bischoffshausen mit ihren Kindern Yrmintrud und Sieglinde sowie einem Hausgast, um 1930 (c) Archiv ZKG schen Soldaten und Offiziere. Die Ehe mit Therese von Oppell war kinderlos geblieben, so dass Niederjahna an den dritten Bruder Curt gelangte. Der Hauptmann der österreichischen Armee starb bereits am 27. Juli 1867 an einer Krankheit. Da der Halbbruder Carl Heinrich von Ende aus zweiter Ehe bereits gestorben war, fiel das Fideikommiss der ältesten Schwester Luise von Ende zu, die zuvor als unverheiratetes Fräulein in Bad Schandau gewohnt hatte. In ihrem Testament vom 12. November 1895 erweiterte sie das Fideikommiss Niederjahna um eine Geldsumme von 50.000 Mark. Als sie am 18. September 1896 ihre Augen schloss, folgte ihr ihre bereits betagte Schwester Anna von Ende (gest. 1898) nach. Auch sie war unverheiratet und kinderlos; 1857/58 war sie im Missionsdienst in Südwestafrika gewesen. Bereits 1898 starb sie, womit ihre Halbschwester Wilhelmine (1833-1914) das Erbe antrat. Die jüngste Tochter Carl von Endes hatte 1866 den Hauptmann Maximilian (Max) von Heineken (1825-1886) geheiratet, einen Nachfahren von Carl Heinrich von Heineken (1707-1791), des Sekretärs des Grafen Heinrich von Brühl

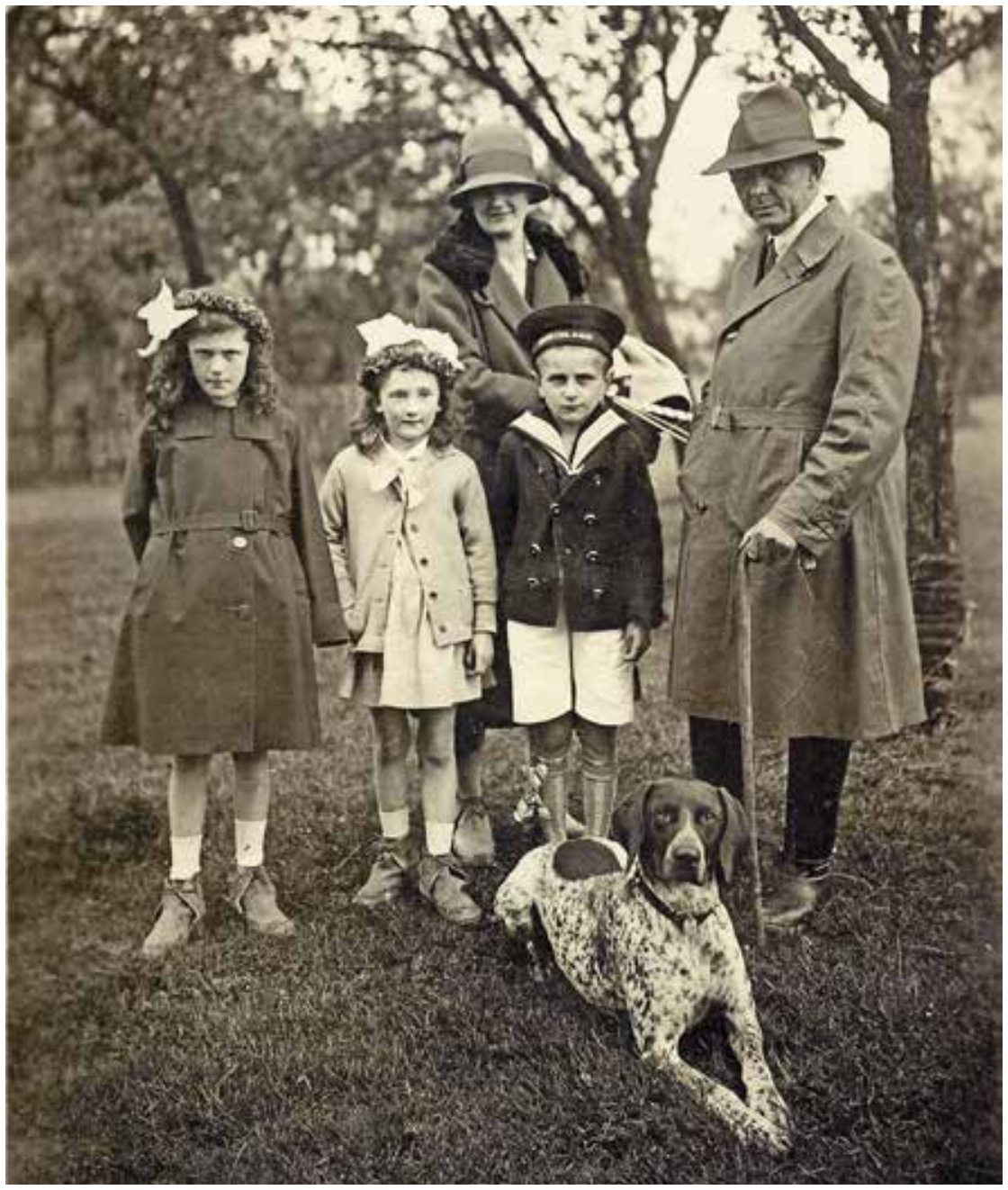

(1700-1763). ${ }^{70}$ Brühl hatte seinem Vertrauten 1763 das Rittergut Bollensdorf bei Dahme/ Mark in der Niederlausitz vermacht, das fortan als Fideikommiss im Besitz der Familie von Heineken blieb. Maximilian und Wilhelmine von Heineken hatten nur eine Tochter, Margarethe von Heineken (1868-1952). Da es keine weiteren männlichen Nachkommen gab, trat der ungewöhnliche Fall ein, dass Margarethe mit Bollensdorf und Niederjahna zwei Fideikommisse übernahm, die eigentlich in männlicher Linie weitergegeben werden sollten. Margarethe hatte 1887 Gotthard Freiherr von Bischoffshausen (1852-1911) geheiratet. Er entstammte einer hessischen Adelsfamilie, die ihren Stammsitz in Berge bei Witzenhausen in Nordhessen hatte. Aus der Ehe gingen drei Kinder hervor: Hildegard (1888-1959), Günther (1890-1971) und Werner (1894-1970). Der älteste Sohn Günther Freiherr von Bischoffshausen, seit 1920 verheiratet mit Petra, geborene Freiin von Hardenberg (1895-1971), bewirtschaftete von 1923 bis 1945 das Rittergut Jahna.

Die Weimarer Reichsverfassung verfügte 1919 die Auflösung aller Fideikommisse, die in Sachsen auch als Familienanwartschaften bezeichnet wurden. Das 1928 verabschiedete „Gesetz über die Auflösung der Familienanwartschaften" regelte, wie in Sachsen die Aufhebung zu vollziehen war. Möglichst durch Beschluss der Anwärter sollten die Fideikommisse aufgehoben und dem jeweiligen Inhaber als freies Eigentum übertragen werden. Abfindungen waren nur für die nächstberechtigten Anwärter vorgesehen. Das mit der Auflösung der Fideikommisse beauftragte Oberlandesgericht Dresden erstellte eine genaue Liste aller Anwärter. Wären die Nachkommen der Wilhelmine von Heineken, also die Mitglieder der Familie von Bischoffshausen, sämtlich gestorben, wäre das Rittergut Jahna an Berechtigte aus der Familie von der Planitz gefallen. Zu den Anwärtern gehörte auch der Kunsthistoriker Prof. Dr. Walter Hentschel (1899-1970). Dies erklärt sich daraus, dass sich die Schwester des Carl von Ende, Henriette Caroline (gest. 1868), mit Julius Edler von der Planitz (1781-1859) vermählt hatte. Ihre Tochter Caroline Luise Thekla Edle von der Planitz wiederum hatte den Zwickauer Unternehmer Friedrich August Hentschel geheiratet, den Großvater Walter Hentschels.

Im März 1929 wurde mit Familienbeschluss die Auflösung der Familienanwartschaft Jahna vollzogen. ${ }^{71}$ Das Rittergut Jahna wurde freies Vermögen. Der erste Anwärter Günther Freiherr von Bischoffshausen wurde abgefunden, indem seine Mutter ihm einen Viertel des Besitzes einräumte. Damit hatte er aber auch ein Viertel der 
Schulden zu übernehmen. Seine Geschwister Hildegard und Werner erklärten, auf Entschädigungen zu verzichten und keine Versorgungsansprüche geltend zu machen. Bis 1945 blieben die Eigentumsverhältnisse so, wie 1929 vereinbart. Günther Freiherr von Bischoffshausen bewirtschaftete das Rittergut, das ihm aber nur zu einem Viertel gehörte. Seine Mutter, die Haupteigentümerin, lebte in Bollensdorf in der Niederlausitz und kam nur gelegentlich nach Niederjahna.

Zum 1. April 1923 wurde das Rittergut Jahna, das bislang eine eigene Gemeinde darstellte, mit der Gemeinde Niederjahna vereinigt. ${ }^{72}$ Beide Seiten mussten aufgrund staatlicher Vorgaben handeln, obwohl sie betonten, diese Vereinigung nicht zu wünschen. Günther Freiherr von Bischoffshausen, der im Namen seiner Mutter verhandelte, erreichte, dass die Gemeinde die Zusage gab, das Herrenhaus nicht mit Zwangsmietern zu belegen, was man angesichts des Wohnungsmangels befürchtet hatte. Mit Inkrafttreten des Vertrags erhielten sämtliche Bewohner des Ritterguts die gleichen Rechte und Pflichten wie die übrigen Bewohner der Gemeinde. Die Gemeindesteuerfreiheit entfiel. Indem der Rittergutsbesitzer nun nicht mehr Gutsvorsteher war, entfiel ein letztes Relikt herrschaftlicher Vergangenheit.

Günther und Petra von Bischoffshausen hatten fünf Kinder. Nach den Regeln des Fideikommisses wäre der älteste Sohn Petermordian (19251945) der Nachfolger geworden, der jedoch im Zweiten Weltkrieg vermisst blieb und vermutlich umgekommen ist. Die Geschwister Yrmintrud (geb. 1921), Sieglinde (geb. 1922), Gisela (geb. 1924) und Gotthard (1931-2003) konnten kein Erbe antreten, da das Rittergut Jahna im Oktober 1945 enteignet wurde. Die Familie von Bischoffshausen verließ am 19. Oktober 1945 abends Niederjahna, um der bevorstehenden Verhaftung und Deportation zu entgehen, und flüchtete mit drei Handwagen in fünf Tagen und vier Nächten nach Berge bei Witzenhausen in Hessen, wo sie von Verwandten aufgenommen wurden. Dort, in der hessischen Heimat der Bischoffshausens, starb am 7. Dezember 1952 im Alter von 84 Jahren Margarethe Freifrau von Bischoffshausen, die letzte Fideikommissherrin von Jahna und Bollensdorf.

\section{Gutswirtschaft}

Gerade bei Betrachtung der Gutsbetriebs ist von Nachteil, dass die Überlieferung des Gutsarchivs weitgehend fehlt. Abrechnungen, Register, Ertragsaufstellungen usw. sind nicht vorhanden. Lediglich für die Jahre zwischen 1900 und 1929 liegt eine dichtere Überlieferung in den Akten des Oberlandesgerichts Dresden vor, das das Fideikommiss Jahna zu beaufsichtigen hatte. ${ }^{73}$ Das Rittergut Jahna war ein eher kleines Rittergut. Als Untertanen hatte es 161118 Bauern und 15 Gärtner, eine im Vergleich zum Rittergut Schleinitz eher bescheidene Zahl. Auch der Umfang der Zinsen und Frondienste war begrenzt. Leider liegt nur für Stroischen ein Erbregister vor, das die Zinsen und Dienste genauer auflistet. ${ }^{74}$ Das Erbregister des Ritterguts Jahna von 1693 ist nur auszugsweise überliefert. ${ }^{75}$ Da sich die Dienstbarkeiten nach dem Einkommen bemaßen, war die Zahl der Bauern (auch Anspänner oder Pferdner) von entscheidender Bedeutung. Die Bauern zahlten an zwei Terminen im Jahr einen Erbzins in Geld und Naturalien. Der Besitzer eines Zweihufenguts musste rund $2 \frac{1}{2}$ Taler entrichten sowie ein Scheffel Roggen, ein Scheffel Hafer, acht alte Hühner und 60 Eier abliefern. Bei den Gärtnern waren die Abgaben um mindestens die Hälfte vermindert. Die Bauern in Stroischen mussten in jedem Jahr jeweils 15 Tage auf den Feldern des Ritterguts Jahna arbeiten und dabei mit ihren Pferden erscheinen. Die 13 Ackertage und 2 Hautage entsprechen vier Prozent der Jahresarbeitszeit. Alles in allem eine Leistung, die das Einkommen der Bauern nur unmerklich schmälerte. Die „Hausgenossen“, also die Einwohner ohne eigenen Grundbesitz, hatten nach dem Erbregister von 1693 jedes Jahr bei der Ernte zwei Tage Rittergutsgetreide zu schneiden. Dieser Dienst war jedoch in eine Geldzahlung umgewandelt worden. Einzelne Hausgenossen zahlten 12 Groschen, Eheleute einen Taler.

1611 wurden die Dienste und Nutzungen mit 10.775 Gulden bewertet. ${ }^{76}$ Das Rittergut bezog aber nicht nur Leistungen von den Untertanen, es hatte auch Pflichten ihnen gegenüber zu erfüllen. So waren den Bauern und Gärtnern aus der Eigenwirtschaft des Ritterguts jährlich 21 Scheffel Roggen „Vor Ihro Kost an Getreyde“ zu liefern. Dabei handelt es sich wohl um die Beköstigung, die den Frondienstleistenden gewährt werden musste. Das wurde 1611 als Beschwernis mit 420 Gulden bewertet.

Die Eigenwirtschaft des Ritterguts war ebenfalls nicht sehr groß. Man verfügte über Felder, Wiesen und Wald überwiegend in der Gemarkung Niederjahna. 1611 wurden die Felder in der Größe von 333 Scheffeln mit 8.400 Gulden bewertet. Die Wiesen gingen mit 200 Gulden in die Berechnung ein, für die Schafhaltung wurden 300 Gulden angesetzt. Der Wald hatte einen Wert von 1.500 Gulden. Den Fischfang im Jahnabach bewertete man mit 400 Gulden. 1847 hatte das Rittergut eine Größe von 108 Hektar
72 HStA Dresden, 10760 , Amtshauptmannschaft Meißen, Nr. 751.

73 HStA Dresden, 11025, Oberlandesgericht Dresden, Nr. 4434.

74 Erbregister vom 20. Dezember 1693, vgl. HStA Dresden, 10084, Appellationsgericht Dresden, Nr. 8738.

75 HStA Dresden, 10424 Grundherrschaft Niederjahna, Nr. 4.

76 LASA Wernigerode, H71, Gutsarchiv Frankleben, Nr. 172 . 
77 HStA Dresden, 10424, Grundherrschaft Niederjahna, Nr. 33, dort auch die folgenden Zahlen.

78 Vgl. HStA Dresden, 10424 , Grundherrschaft Niederjahna, Nr. 80; 10084, Appellationsgericht Dresden, Nr. 8247; 10057, Kreisamt Meißen, Nr. 1689.

79 HStA Dresden, 10084, Appellationsgericht Dresden, Nr. 8928.

80 HStA Dresden, 10424, Grundherrschaft Niederjahna, Nr. 163.

81 HStA Dresden, 10424, Grundherrschaft Niederjahna, Nr. 22,24

82 HStA Dresden, 10424, Grundherrschaft Niederjahna, Nr. 4. 83 Gröger 1937, S. 69-70.

84 Gröger 1937, S. 72-73.
(268 Acker 13 Ruten). Über die angebauten Feldfrüchte ist nur wenig bekannt. Das wichtigste Brotgetreide war der Roggen. 1847/48 wurden auf den Feldern Raps, Rüben, Weizen, Roggen, Gerste, Hafer, Erbsen, Wicken, Linsen, Hirse, Hanf, Lein, Klee und Kartoffeln angebaut - angesichts der doch begrenzten Fläche eine erstaunliche Vielfalt.

Zur Eigenversorgung gehörte auch die Viehhaltung. Eine wichtige Einnahme war die Schafhaltung, die nur den Rittergütern erlaubt war. 1834 umfasste die Schafherde 442 Schafe. ${ }^{77}$ Ansonsten waren die Stückzahlen eher gering. In den Ställen standen 183425 Kühe und Kälber, 26 Schweine und zwei Ziegen. Carl von Ende verfügte über sieben Pferde, davon drei Kutschpferde. Für den Ackerbau hatte er vier Arbeitspferde und drei Ochsen. Die geringe Zahl der Zugtiere lässt erkennen, welchen hohen Handarbeitsanteil man noch im 19. Jahrhundert ansetzen muss.

Die Untertanen hatten gemäß dem Erbregister nicht nur bei der Landwirtschaft zu helfen, sie mussten auch weitere Leistungen erbringen. Alle Untertanen mussten Lehngeld entrichten. Das bedeutet, dass bei jedem Verkauf eines Hauses oder Grundstücks ein Prozent der Kaufsumme abzuführen war. ${ }^{78}$ Darüber hinaus hatten sie für die Gutsherrschaft Bau-, Schutt-, Dünger- und Erntefuhren durchzuführen. 1663 verklagten die Bauern in Nimtitz und Mehren Joachim Heinrich von Schleinitz, weil sie nicht bereit waren, Bauholzfuhren zu leisten. ${ }^{79} \mathrm{Im}$ Erbregister für Stroischen wurde die umstrittene Leistung 1693 in eine Zahlung umgerechnet. Jeder Bauer musste einen Taler 15 Groschen Holzfuhrengeld bezahlen und war seitdem von Holzlieferungen befreit.

Zu den Herrschaftsrechten des Ritterguts gehörte auch die Gerichtsbarkeit über die Untertanen. Sie umfasste in Niederjahna und Nimtitz auch alle schweren Vergehen und damit sowohl die niedere als auch die obere Gerichtsbarkeit. In den anderen Dörfern übte das Rittergut Jahna die niedere und das Amt Meißen die obere Gerichtsbarkeit aus. Gerichtsort war das Jahnaische Freihaus in Meißen, weshalb man auch vom „Jahnaischen Freyhausgericht zu Meißen“ sprach. Die Streitfälle wurden von ausgebildeten Juristen entschieden. Einer der Gerichtsdirektoren war der Meißner Rechtsanwalt Dr. Ernst Siegismund Beuchel, dem 1778 sein Sohn Carl Sigismund Beuchel nachfolgte. ${ }^{80}$

Mehrfach gab es Gerichtsverfahren zu Diensten, die von den Untertanen angezweifelt oder verweigert wurden. Das betraf besonders die Fälle, in denen Umfang und Dauer der Leistung nicht im Erbregister festgelegt waren. Lange wurde um das Holzschlagen gestritten, zu dem die Gärtner in Niederjahna und Nimtitz verpflichtet waren. ${ }^{81}$ Marie Sophie von Theler forderte sie 1757 auf, das Holz in kleine Scheite zu schlagen und so viel Feuerholz zu bereiten, wie sie es im Rittergut Jahna und in ihrem Freihof in Meißen benötige. Der Advokat Sigismund Gottlob Scheuffler, der die Fröner vertrat, argumentierte, nach strenger Auslegung des Erbregisters sei zwar Feuerholz zu schlagen, keineswegs aber werde gefordert, das Holz in kleine Scheite $\mathrm{zu}$ spalten. Außerdem sage das Erbregisters nichts über die Versorgung des Jahnaischen Hofs mit Feuerholz. 1759 forderte Johann Friedrich von Theler die Gärtner in Niederjahna und Nimtitz auf, das Holz so zu schlagen, „daß es sofort auf dem Herde und in denen Öfen zum Anlegen gebrauchet werden kann", und drohte mit einer Strafe von 10 Talern. Die Auseinandersetzung zog sich über Jahrzehnte hin. 1819 wurde die Akte ohne Urteil geschlossen. 1818 verweigerten sieben Hausbesitzer in Questenberg die Schnitterdienste bzw. die dafür angesetzte Geldzahlung. Carl von Ende verklagte sie in einem aufwendigen Verfahren, das bis vor die Juristenfakultät in Leipzig ging. ${ }^{82}$ Aus der Akte geht nicht hervor, ob die Untertanen der Zahlungspflicht nachgekommen sind.

Als am 25. Januar 1770 Magdalena Friederike von Theler starb, die Ehefrau des Rittergutsbesitzers, forderte der Gerichtsdirektor Dr. Ernst Sigismund Beuchel die Untertanen des Ritterguts Jahna auf, zur Totenwache im Jahnaischen Freihof in Meißen zu erscheinen, wo die Verstorbene aufgebahrt war. Doch die Einwohner weigerten sich einstimmig, dort zu erscheinen, und wiesen darauf hin, dass Meißen nicht Jahna sei und sie deshalb nicht zur Totenwache verpflichtet werden könnten. ${ }^{83}$ Das zeugt von einem erheblichen Widerspruchsgeist, zumal der Jahnaische Freihof nur formal ein eigenes Lehen darstellte. 1790 wurde auch Jahna von dem Bauernaufstand in der Lommatzscher Pflege erfasst. Am 21. August 1790 warnten die „Hochadelig Thelerschen Gerichte“ die Untertanen vor Widerstand, Zusammenrottung und Aufruhr. Die Bewohner der Dörfer antworteten drei Tage später mit einem Brief, in dem sie alle Dienstverpflichtungen aufkündigten, was alle Bauern, Gärtner und Häusler mit ihrer Unterschrift bekräftigten. Doch als Anfang September kursächsischen Militär in Meißen erschien, brach der Aufstand zusammen. Die Untertanen mussten sich wieder mit ihren Dienstpflichten abfinden. Am 23. September 1790 mussten die reumütigen Bauern vor Christian Wilhelm von Theler erscheinen und ihm Mann für Mann den Handschwur leisten. ${ }^{84}$ 
Der Bauernaufstand hatte gezeigt, dass Reformen unumgänglich waren und die vormoderne Agrarordnung nicht mehr fortbestehen konnte. Die Agrarreformen, die im Königreich Sachsen seit 1831 durchgeführt wurden, beseitigten auch in Niederjahna die Dienstpflichten. Bei der Ablösung, die 1833 begann und 1841 beendet wurde, rechnete man sämtliche Dienste in einen Geldwert um. ${ }^{85}$ Dieser Geldbetrag war jährlich zu zahlen. Er konnte aber durch eine Einmalzahlung oder durch eine Ratenzahlung an die Landrentenbank abgelöst werden. Der Ablösungsrezess für das Rittergut Jahna wurde am 3. April 1841 unterzeichnet. Er erfasste 51 Untertanen mit 53 Besitzungen. Die Landrentenbank schrieb Carl von Ende einen Betrag von 6.562 Talern und 13 Groschen gut, der eine Jahresrente von 262 Talern 20 Groschen erbrachte. ${ }^{86}$ Diese Summe konnte aber keinesfalls den Wegfall der Dienstpflichten ersetzen, da sie bei weitem nicht ausreichte, um die entfallenen Leistungen durch Lohnarbeit zu ersetzen.

Nach den Agrarreformen blieb nur die Eigenwirtschaft des Ritterguts Jahna bestehen, während die Herrschaftsrechte erloschen. Das Lehngeld wurde im Vertrag vom 18. Januar 1853 durch eine Zahlung an die Landrentenbank abgelöst. ${ }^{87}$ Zuletzt musste 1856 die Gerichtsbarkeit an den sächsischen Staat abgetreten werden.

Der Landwirtschaftsbetrieb war teils an Pächter vergeben, teils wurde er in eigener Verantwortung der Fideikommissinhaber durch Verwalter geführt. Der älteste überlieferte Pachtvertrag wurde 1681 zwischen den Brüdern von Schleinitz und dem Pächter Valentin Fischer (16491731) abgeschlossen. ${ }^{88}$ Dieser war später Verwalter des kurfürstlichen Kammerguts Gorbitz. Für das 18. und 19. Jahrhundert lassen sich mehrere Verwalter nachweisen. So war 1759 ein Adam, Sohn des Gartennahrungsbesitzers George Adam, herrschaftlicher Verwalter. 1832 hatte Johann Herrmann Oehmigen, wohl ein Mitglied der in Lommatzscher Pflege begüterten Familie Oehmichen, die Verwaltung inne. Von 1847 bis 1853 war das Rittergut an Carl Gottlieb Starke aus Mehren verpachtet, der jährlich 3.200 Taler entrichtete. ${ }^{89}$ Von seiner Pacht waren das Herrenhaus, das Freihaus in Meißen, die Gerichtsbarkeit, der Wald, das Jagdrecht sowie Teile des Gartens ausgenommen.

Am 19. März 1864 verpachtete Arthur von Ende das Rittergut Jahna an Julius Oskar Gießmann, bisher Verwalter des Ritterguts Löthain..$^{90}$ Dieser Pachtvertrag wurde immer wieder verlängert, und so gelang es der Familie Gießmann, 60 Jahre lang die Geschicke Niederjahnas zu bestimmen. Die Verpachtung garantierte den

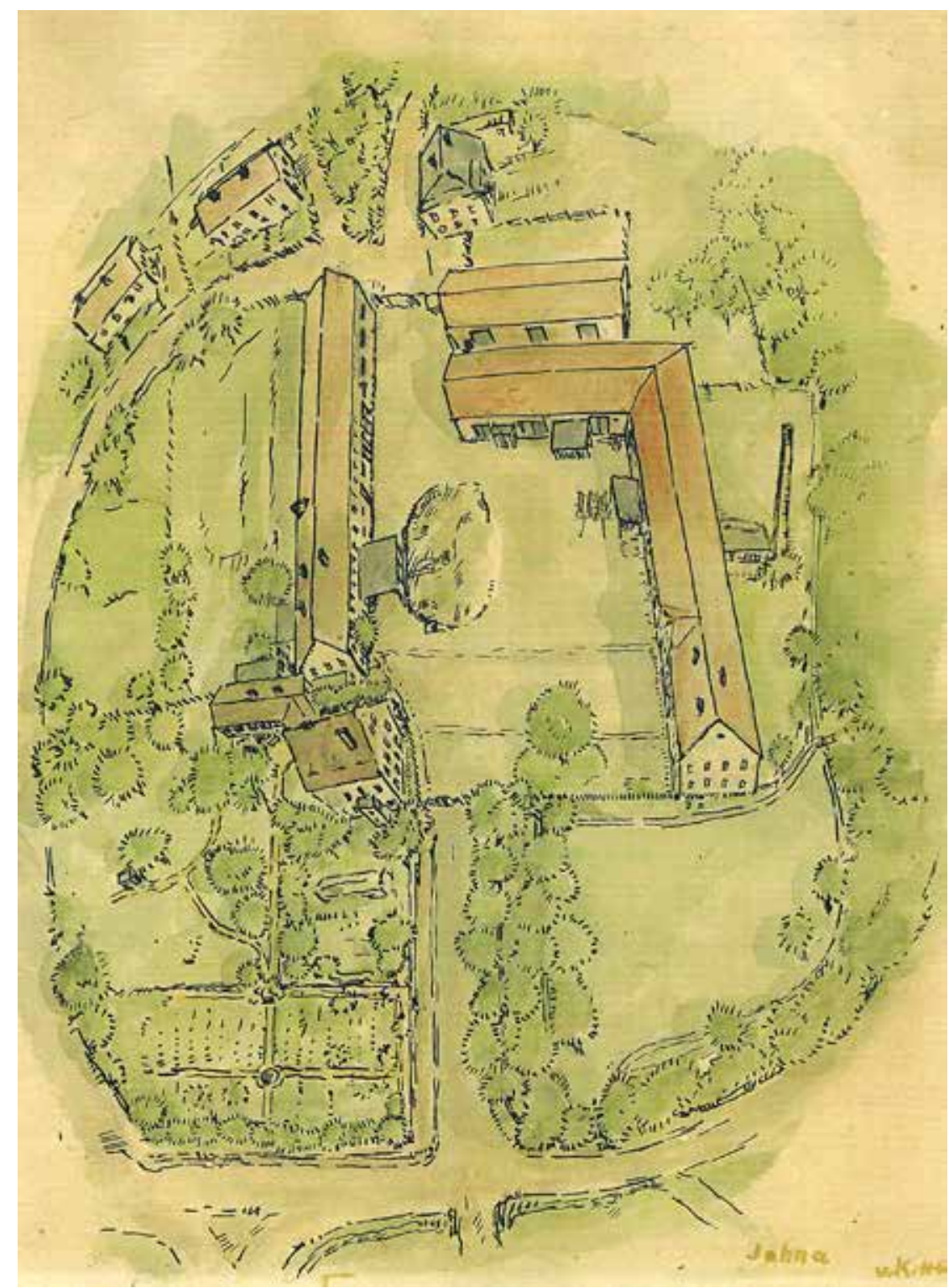

wechselnden, seit 1867 ausschließlich weiblichen Fideikommissinhabern ein sicheres Einkommen, ohne dass sie sich als Landwirte betätigen mussten. Die Pacht betrug in den ersten beiden Jahren 2.600 Taler, dann 3.600 Taler, umgerechnet 10.800 Mark. Nach der Jahrhundertwende stieg die Pacht auf 12.000 Mark. Allerdings war aus den Erträgen auch der bauliche Unterhalt der Gebäude zu bestreiten. 1864/65 hatte Arthur von Ende zwei neue Wirtschaftsgebäude und eine Scheune erbauen lassen. Seitdem gehörte zum Rittergut eine Brennerei. Aus Kartoffeln wurde Spiritus gewonnen, der auch zum Antrieb der Dampfmaschine diente. Diese trieb eine Dresch- und Häckselmaschine an.

Wiederholt musste geklärt werden, ob das Betriebsinventar Teil des Fideikommisses ist, zum Allodialvermögen gehört oder Eigentum des Pächters ist. So forderten Arthur und Curt von Ende, die Söhne des 1849 verstorbenen Carl
Schaubild des Ritterguts Jahna, Aquarell, vor 1945. Links unten das Herrenhaus mit dem Garten, oben in der Mitte das Pächterhaus (c) Archiv ZKG

85 HStA Dresden, 10424, Grundherrschaft Niederjahna, Nr. 77 80.

86 Gröger 1937, S. 79-81, vgl. HStA Dresden, 10424, Grundherrschaft Niederjahna, Nr. 77.

87 HStA Dresden, 10424, Grundherrschaft Niederjahna, Nr. 80

88 LASA Wernigerode, H71, Gutsarchiv Frankleben, Nr. 198.

89 HStA Dresden, 10424, Grundherrschaft Niederjahna, Nr. 35

$90 \mathrm{Zu}$ Julius Oskar Gießmann vgl. Dietrich Sieber: Von Schafen und Menschen und sonstigen Geschöpfen. Eine sächsische Chronik. Gelnhausen 2000, S. 99-103. 
Herrenhaus Niederjahna, Wappentafel an der Giebelseite Foto: Matthias Donath

91 HStA Dresden, 10057, Kreisamt Meißen, Nr. 1004.

92 Sieber 2000, S. 99-103.

93 Vgl. HStA Dresden, 11025 , Oberlandesgericht Dresden, Nr. 4435-4436, dort auch die folgenden Angaben.

94 Niekammers Landwirtschaftliche Güter-Adreßbücher. Bd. IX. Freistaat Sachsen. Leipzig 1925, S. 249

95 Das Herrenhaus wurde bisher kaum von der historischen, kunsthistorischen und heimatkundlichen Forschung beachtet. Zum älteren Forschungsstand vgl. Cornelius Gurlitt: Beschreibende Darstellung der älteren Bau- und Kunstdenkmäler in Sachsen. Bd. 41. Amtshauptmannschaft Meißen-Land. Dresden 1923, S. 586-588; Matthias Donath: Schlösser im Elbland. Dresden 2004, S. 64-65; 800 Jahre Niederjahna. Ein Streifzug durch die Geschichte. Niederjahna 2005, S. 5-7.

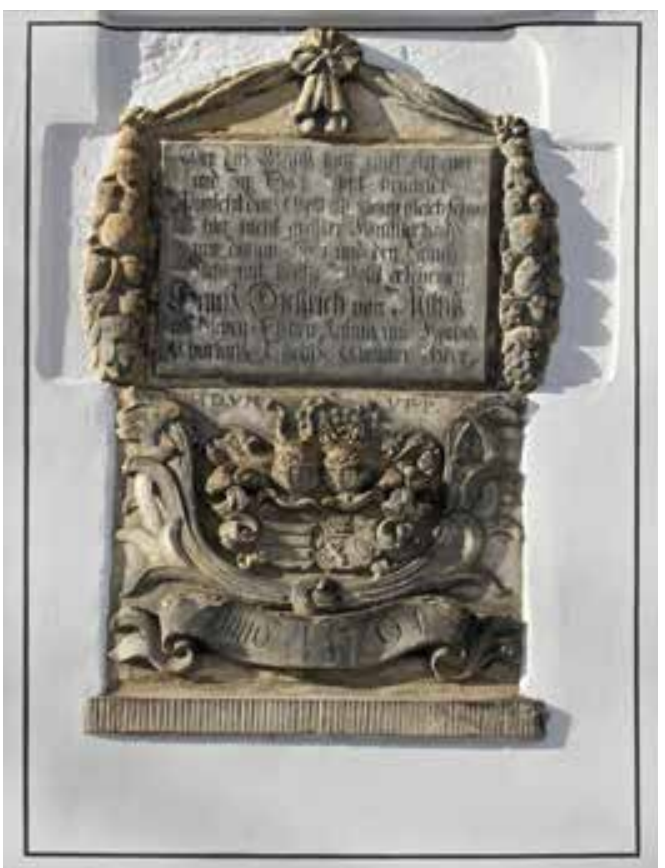

von Ende, ihren Anteil am Gutsinventar, was der älteste Sohn Oskar von Ende verweigerte. Er konnte sich durchsetzen. Das Königlich Sächsische Spruchkollegium zu Leipzig entschied, dass das Inventar nach Willen des Fideikomissstifters Friedrich Wilhelm von Thumshirn dem jeweiligen Fideikommissinhaber zufalle. ${ }^{91} 1864$ veräußerte Arthur von Ende sämtliches Inventar an den Pächter Julius Oskar Gießmann.

Aus den Erinnerungen von Dr. Otto Steiger (1851-1935) auf Löthain, der 1868 bis 1870 bei Julius Oskar Gießmann in Jahna eine Landwirtschaftslehre absolviert hatte, geht der Tagesablauf auf dem Rittergut hervor. ${ }^{92}$ Die Hoftore waren nachts geschlossen und mussten früh aufgeschlossen werden. Arbeitsbeginn war im Sommer um 5 Uhr und im Winter um 6 Uhr. 11 Uhr begann die Mittagspause, pünktlich um 12 Uhr wurde gegessen, und 13 Uhr begann die Arbeit wieder, die, mit Unterbrechung durch die Vesper, erst 19 Uhr endete. Nach dem Abendessen notierte der Pächter die Ereignisse des Tages in ein Tagebuch, dann kontrollierte er durch Ableuchten alle Ställe. Um 21 Uhr war Schlafenszeit.

Die Inflation und die „Agrarkrise“ nach dem Ersten Weltkrieg forderten erhebliche Umstellungen. Die Pachtsumme reichte kaum noch aus, um die Erhaltungskosten für die Gutsgebäude aufzubringen. Daher entschloss sich Günther Freiherr von Bischoffshausen, der älteste Sohn der Fideikommissinhaberin, das Rittergut in eigene Bewirtschaftung zu nehmen.93 Durch das Einsetzen der eigenen Arbeitskraft und durch die Ausschaltung des Pächterge- winns versuchten seine Mutter und er, „die Familienanwartschaft mit allen Mitteln durch die gegenwärtige schwere Zeit hindurchzuretten“. Doch der Pachtvertrag lief zu einem denkbar ungünstigen Zeitpunkt aus, am 30. Juni 1923, als der Währungsverfall seinen höchsten Stand erreichte. Sämtliches Kapital, das zum Fideikommiss Jahna gehörte, war wertlos geworden. Dabei wäre das Geld dringend gebraucht worden, um Max Oskar Gießmann (1871-1913) das Betriebsinventar abzukaufen, das 1864 in den Besitz des Pächters übergegangen war. Nun musste Gießmann für sämtliche Geräte, Gegenstände, Vorräte und Tiere, auf den Feldern wie auf dem Gutshof, entschädigt werden. Anstelle der wertlosen Mark setzte man einen Gegenwert von 4.000 Zentnern Roggen fest. Diese und andere Zahlungen wurden als Hypothek ins Grundbuch eingetragen. Außerdem lieh sich Günther Freiherr von Bischoffshausen von seinem Verwandten Hans Carl Freiherr von Bischoffshausen den Gegenwert von 98 Zentner Roggen, um sich Kunstdünger zu kaufen. 1924 kaufte er eine Künzel-Kleinod-Hackmaschine, eine Ringelwalze und eine Hackewalze - ein erster Schritt hin zum Maschineneinsatz auf den Rittergutsfluren.

1923 waren 72 Hektar Ackerland bebaut. Auf 44 Hektar wuchsen Halmfrüchte und auf 14 Hektar Kartoffeln und Rüben. 14 Hektar wurden für die Gewinnung von Grünfutter genutzt. Der Viehbestand war immer noch gering. Man zählte 43 Stück Rindvieh, darunter der Herdzuchtbulle „Herzbube“, 16 Schweine, davon fünf Zuchtsauen, 262 Schafe, 41 Hühner und 80 Tauben. Als Zugtiere standen 12 Pferde bereit. Aus den erhaltenen Unterlagen lässt sich nicht ersehen, inwieweit Günther Freiherr von Bischoffshausen betriebswirtschaftliche Veränderungen vornahm. Nach dem Güteradressbuch von 1925 umfasste das Rittergut Jahna 152 Hektar, davon 117 Hektar Ackerland, 12 Hektar Wiesen und 16 Hektar Wald. ${ }^{94}$ Der Viehbestand umfasste 12 Pferde, 52 Rinder, 40 Schweine und 300 Schafe, was nicht auf eine größere Veränderung hindeutet.

Die überlieferten, bis 1929 reichenden Aufzeichnungen geben nicht zu erkennen, dass die 1923/24 aufgenommenen Schulden, die rund 45.000 Reichsmark entsprachen, getilgt worden wären. Vielmehr wuchs die Schuldenlast weiter an. So wurde 1925 ein Kredit des Landwirtschaftlichen Kreditvereins Sachsen über 30.000 Reichsmark eingetragen und vor 1929 nochmals ein Lombarddarlehen über 12.000 Reichsmark aufgenommen. Ein Brief der Margarethe von Bischoffshausen vom 11. April 1928 belegt, dass im Wirtschaftsjahr 1927 ein Verlust von 
14.000 Reichsmark entstanden war und dass man überlege, Kredithilfe zu beantragen. Es war vermutlich nicht das einzige Jahr, in dem die Einnahmen nicht die Ausgaben deckten und jeglicher Ertrag fehlte. Da die Agrarkrise weiter anhielt, ist nicht davon auszugehen, dass sich die finanziellen Verhältnisse besserten. Die Familie von Bischoffshausen lebte unter diesen Umständen weitgehend von der Selbstversorgung. Nur durch eine durchgreifende Modernisierung, den Einsatz von Landtechnik und die Minderung des Personalaufwands hätte das Rittergut Niederjahna, das 1929 mit rund 77.000 Reichsmark verschuldet war, wieder rentabel gemacht werden können, doch ist dieser Prozess durch den Zweiten Weltkrieg gestoppt und durch die Enteignung abrupt beendet worden.

\section{Herrenhaus, Hofgebäude,} Garten und Park

Das Herrenhaus ist das älteste Bauwerk in Niederjahna. ${ }^{95}$ Es wurde nach 1579 durch Hans von Schleinitz und Maria von Sundhausen errichtet, wie die Wappen in den Zwickeln des Rundbogenportals belegen. Der zweigeschossige Bau folgt mit seiner einfachen Gestalt ohne Turm und dem steilem Satteldach noch stark der spätgotischen Bautradition. Verwandte Herrenhäuser sind das Alte Schloss in Borthen, erbaut 1543, und das Herrenhaus des Ritterguts Neubau in Frankenberg/Erzgebirge, erbaut 1553/54. Zahlreiche Sandstein-Gewände innen wie außen sind noch aus dieser Zeit erhalten. In allen drei Etagen sind mittig Vorsäle ausgebildet, die jeweils durch die gesamte Gebäudetiefe reichen und an die sich links und rechts die einzelnen Räume anschließen. So gelangt man im Erdgeschoss zunächst in eine tiefe Halle, an dessen Ende eine Treppe ins Obergeschoss führt. Ein Gewölberaum im Erdgeschoss wird durch eine Rundbogentür erschlossen, die mit einer geschmiedeten Eisentür verschlossen ist. Aufgelegt waren ehemals bemalte Wappenschilde, von denen allerdings nur verrostete Reste geblieben sind - vermutlich die Wappen des Bauherrn und seiner Vorfahren. In einer zweiten Schicht hatte man die Wappen von Hans Dietrich von Miltitz und seiner Frau aufgenietet, die 1923 noch sichtbar waren. Aus Vergleichen lässt sich ersehen, dass dieser, durch Gewölbe und Eisentür vor Feuer geschützte Raum als Archiv genutzt worden war. Daneben befand sich die Schwarzküche, deren Fundamentzone archäologisch 2011/12 untersucht wurde.

Um 1691 führte Hans Dietrich von Miltitz einen größeren Umbau durch. Dabei blieb die äußere Gestalt des Hauses weitgehend erhalten, doch wurden Innenwände eingezogen, neue Fenster und Sandsteingewände eingebaut und die Giebel verändert. Zwei Sandsteinreliefs erinnern an diesen Umbau: Über dem Portal wurde eine Tafel ergänzt, die Hans Dietrich von Miltitz kniend und betend vor dem Kruzifix zeigt. Dieses ist von den seinem Wappen und dem seiner Frau umgeben, die mit „D. v. Miltitz" und „D. Pfluge“ beschriftet sind. Ein Schriftband enthält die Inschrift: „Christi Blut allein / Macht mich von Sünden reyn“, unten ist als Datierung „A. 1691“ angegeben. An der Ostseite wurde über einem damals neu geschaffenen Eingang eine größere Sandsteinplatte mit folgender Inschrift angebracht: „Der diß Haus hatt auff gebaut / und zu Ende Steht benandt / Wünscht daß Gott ob man gleich Schaut / hier nicht großer Künstler hand / nur darinn Ihm und den Seinen / Stets mit hülffe Wohl erscheinen / Hanß Diettrich von Miltitz / uff Sieben-
Herrenhaus Niederjahna, Kaiserdecke im Flur des ersten Obergeschosses, Ausschnitt Foto: Matthias Donath

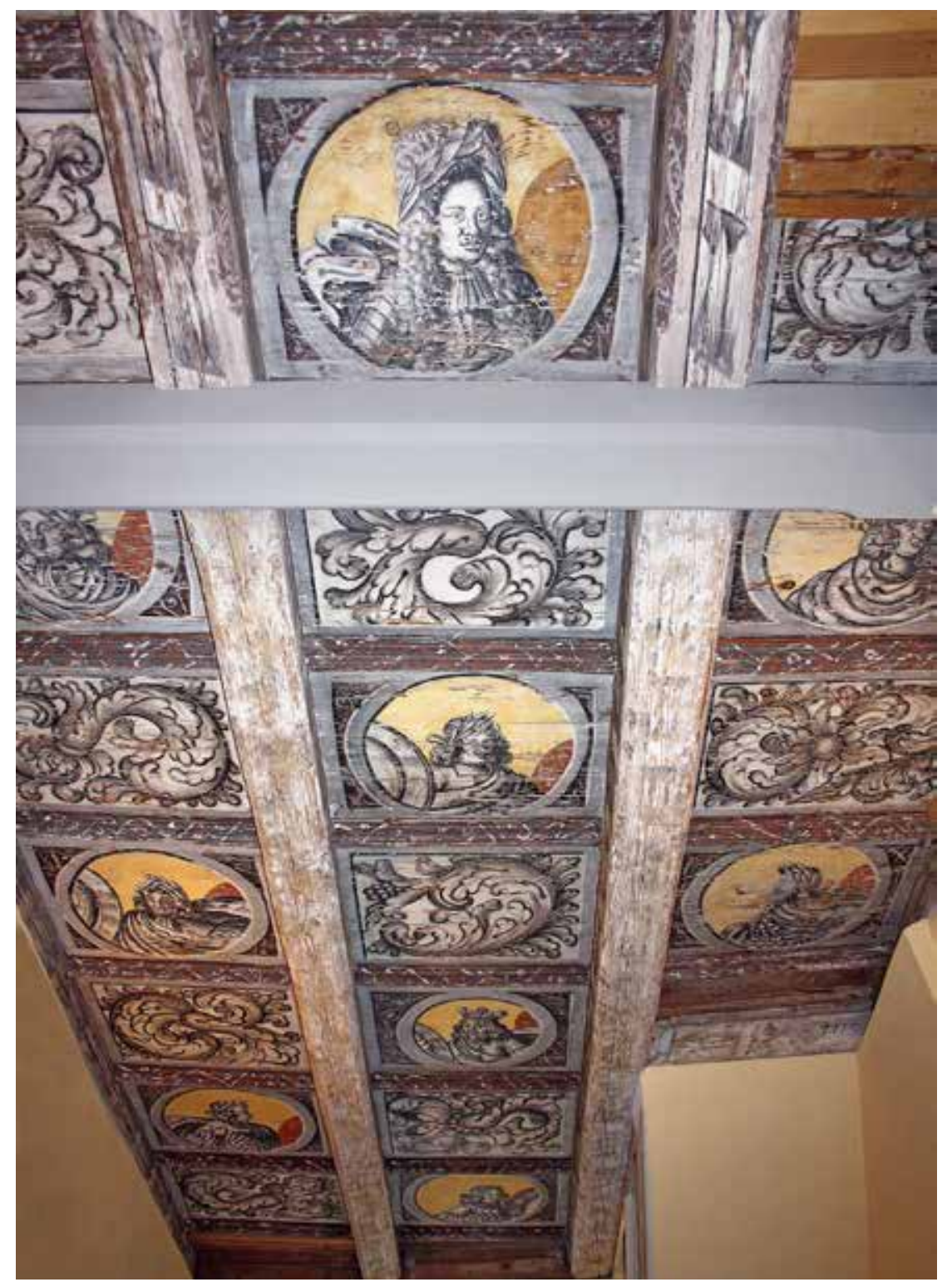




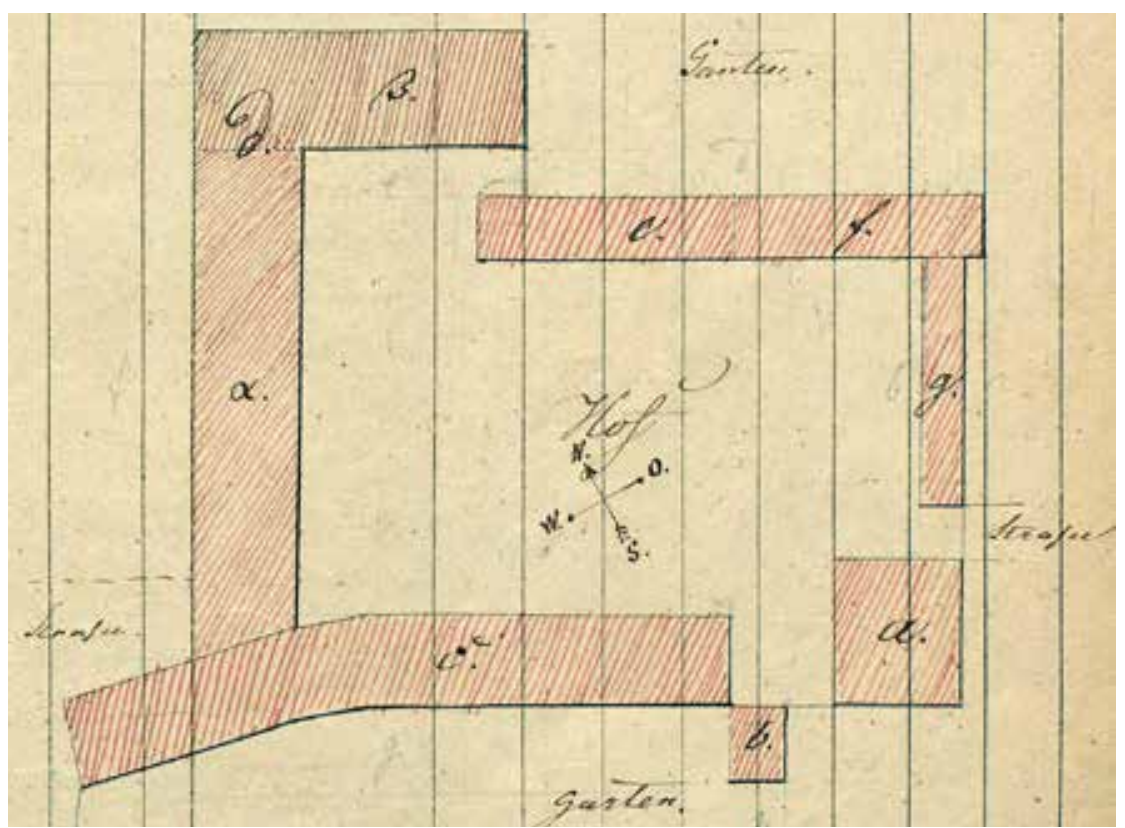

Rittergut Jahna, Lageplan der Gutsgebäude, 1837 (๑) Archiv ZKG
96 Die Deckenbemalungen sollen an anderer Stelle ausführlich publiziert werden. $\mathrm{Zu}$ ersten Ergebnissen vgl. Matthias Donath: Künstlerische Ausgestaltung von Adelsschlössern. In: Martina Schattkowsky (Hrsg.): Adlige Lebenswelten in Sachsen. Kommentierte Schrift- und Bildquellen. Köln/Weimar/ Wien 2013, S. 124-132; Matthias Donath: Medium of Communication or Reaffirmation? The Emblematic Ceiling of Niederjahna Manor. In: Ingrid Höpel/Simon McKeown (Hrsg.): Emblems and Impact. Volume II. Von Zentren und Peripherie der Emblematik. Cambridge 2017, S. 707-718.
Eichen Jahna und Korbitz / Churfürstl. Sächß. Cammer Herr“. Darüber befinden sich sein Wappen und das seiner Frau Ursula Perpetua Pflug, versehen mit den Monogrammen HDVM und VPP. In einem Schriftband erscheint: „Anno 1691“.

Die bedeutendste künstlerische Hinterlassenschaft dieses Umbaus sind die bemalten Holzbalkendecken, die sich in allen Etagen befinden. ${ }^{96}$ Sie waren nahezu 300 Jahre durch untergehängte Decken verdeckt und sind erst zwischen 1999 und 2017 schrittweise freigelegt worden. Den sichtbar gelassenen Deckenbalken sind jeweils Bretter aufgelegt, wobei profilierte Untergliederungen eine Kassettenteilung vornehmen. Mehrere dieser Decken sind nur ornamental dekoriert, mit Ranken, Palmetten und ähnlichen Gebilden vor marmorierten Hintergründen. Drei Räume erhielten figürliche Bemalungen. So besitzt der Vorsaal eine Decke, bei der sich Felder mit Rankenwerk mit runden Medaillons abwechseln. Diese zeigen Porträts römischer und römisch-deutscher Kaiser von Julius Cäsar bis Leopold I., damals der regierende Kaiser in Wien. Dieses Bildprogramm ist als Treuebekenntnis zu Kaiser und Reich zu verstehen. Während die Decke der westlichen Giebelstube im Dachgeschoss mit asiatischen Landschaften bemalt wurde, die ein äußerst frühes Zeugnis der Chinamode in Sachsen darstellen, erhielt die östliche Giebelstube eine emblematische Bilderdecke. Die Embleme, eine seit dem 16. Jahrhundert beliebte Kunstform aus Text und Bild, wurden einem Emblembuch entnommen, den „Emblematischen Gemüts-Vergnügungen“, gedruckt 1693 in Augsburg. Aus der Auswahl der Motive, die jeweils mit französi- schen Motti versehen sind, lässt sich erschließen, dass Hans Dietrich von Miltitz hier Lebensregeln für ein kluges Handeln in Staat und Familie zusammenstellen ließ. Die beiden Räume im Dachgeschoss dürften trotz ihrer repräsentativen Gestaltung als private Schlafstuben genutzt worden sein. Ohne öffentlichen Zugang diente die Emblemdecke wohl vor allem der Selbstdarstellung und Selbstvergewisserung des adligen Hausherrn.

Die farbigen Decken wurden bereits 1724 verkleidet, wohl weil sich der Geschmack geändert hatte, vielleicht auch, um die Wärmdämmung $\mathrm{zu}$ verbessern und den Brandschutz zu erhöhen. Die Datierung ergibt sich aus einer Kreideinschrift, die zwei der beteiligten Arbeiter hinterlassen haben. Sie notierten: „Verbaud / 1724

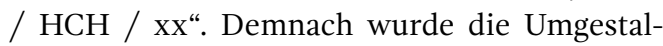
tung der Innenräume durch Friedrich Wilhelm von Thumshirn veranlasst, den Stifter des Fideikommisses. Damals wurde auch der Saal im Obergeschoss barockisiert. Man schlug die Konsolen der Renaissance-Wandbogengliederung ab und baute eine Stuckdecke mit Voute und einfacher Profilierung ein.

Das Herrenhaus blieb größtenteils im Zustand des 17. und 18. Jahrhunderts erhalten, weil spätere Besitzer entweder nicht im Haus wohnten oder für eine Modernisierung kein Kapital hatten. Im 18. Jahrhundert lebten die Fideikommissinhaber überwiegend im Jahnaischen Hof in Meißen. Um 1820 wurde das Herrenhaus wieder von einer größeren Familie bewohnt, von Carl von Ende und seinen Kindern, und für ihren Bedarf angepasst und modernisiert. Doch nach dem Tod von Carl und Caroline Luise von Ende stand das Herrenhaus über Jahrzehnte weitgehend leer. Die Schwestern Luise und Anna von Ende bewohnten den Freihof in Meißen, ihre Halbschwester Wilhelmine von Heineken lebte seit 1866 in Bollensdorf bei Dahme/Mark, wo auch ihre Tochter Margarethe Freifrau von Bischoffshausen, die letzte Inhaberin des Fideikommisses, ihren Hauptwohnsitz hatte. Sie kam nur zu gelegentlichen Besuchen nach Meißen und Niederjahna. Erst nach dem Ersten Weltkrieg wurde das Herrenhaus wieder zum Leben erweckt, indem Günther Freiherr von Bischoffshausen und seine Frau Petra nach Niederjahna zogen, wo sie die Bewirtschaftung des Gutes übernahmen. Da das Haus bis dahin weder über einen Wasseranschluss noch Toiletten verfügt hatte, wurde an der Südseite 1938 ein Toilettenanbau errichtet.

Im Winkel zum Herrenhaus steht ein kleineres Seitengebäude. Es ist zur Hälfte in das nach Westen ansteigende Hanggelände eingetieft. Im Erdgeschoss befinden sich zwei fensterlose Kel- 
lertonnen, die nach der Beschreibung von 1837 „zur Aufbewahrung von Feldfrüchten“ dienten. Nach ihnen wurde das Gebäude 1837 als „Kellerhaus" bezeichnet. Das steinerne Obergeschoss war mit einem Satteldach bedeckt und besaß Renaissancegiebel, was auf eine Errichtung im 16. oder 17. Jahrhundert hindeutet. Das Obergeschoss wurde 1886 abgetragen. Luise von Ende, die sich modernere Wohnräume wünschte, ließ eine neue Wohnetage aufsetzen. $\mathrm{Zu}$ ihr gehört ein nach Süden gerichteter, großflächig verglaster Wintergarten. Der neu geschaffene Wohnbereich wurde durch einen Übergang mit dem Herrenhaus verbunden. Nach 1914 ließ Margarethe Freifrau von Bischoffshausen diesen Gebäudeteil nochmals modernisieren und verändern.

Die Gutsgebäude stammen in der heutigen Gestalt überwiegend aus der zweiten Hälfte des 19. Jahrhunderts. Den älteren Zustand gibt eine Skizze aus dem Jahr 1837 wieder, der dem Brandkataster beigefügt ist. ${ }^{97}$ Der Plan gibt zu erkennen, dass der Wirtschaftshof früher kleiner war und das Herrenhaus enger umgab. Der Kuhstall (g) bildete den südlichen Abschluss des Hofs. Seine Außenwand lag mit der Außenmauer des Herrenhauses in einer Flucht. So erklärt sich, warum sich im Ostgiebel des Herrenhauses ehemals ein Portal befand, das später zu einem Rechteckfenster verkleinert wurde, denn dieser Eingang führte unmittelbar auf den Gutshof. 1837 war auch noch ein Stallgebäude (e) mit Verwalterwohnung (f) vorhanden, die den Hof nach Norden begrenzten. Die weiteren Gebäude entstammen einem Ausbau des 18. Jahrhunderts, bei dem der Hof weiter gefasst wurde. Auf der Westseite befindet sich das Kuh- und Schafstallgebäude (c), an welches sich die sogenannte Winkelscheune (d) anschließt. Der ältere, östliche Teil wurde 1785 durch Christian Wilhelm von Theler erbaut, während der Teil, der den Hof nach Norden begrenzt, 1836/37 durch Carl von Ende hinzugefügt wurde. 1864/65 ließ Arthur von Ende einen großen Teil der Gutsgebäude neu errichten. ${ }^{98}$ Anstelle des Kuh- und Schafstalls (c) entstand ein neues Gebäude. Es enthielt im Erdgeschoss Milchkammer, Kuhstall, Schweinestall und Schafstall, während im Obergeschoss die Wohnungen des Pächters und Inspektors sowie ein Heuboden eingerichtet waren. Von der 1837 erbauten Scheune wurde ein Teil abgerissen, um eine nördliche Hofzufahrt zu gewinnen. Hinter den nördlichen Arm der Winkelscheune wurde eine zweite große Scheune gesetzt. Schließlich wurde an der Ostseite des Gutshofs nach Abbruch der älteren Gebäude (e) bis (g) an die Winkelscheune ein östliches Wirtschaftsgebäude angebaut. Es enthielt die Brennerei, den

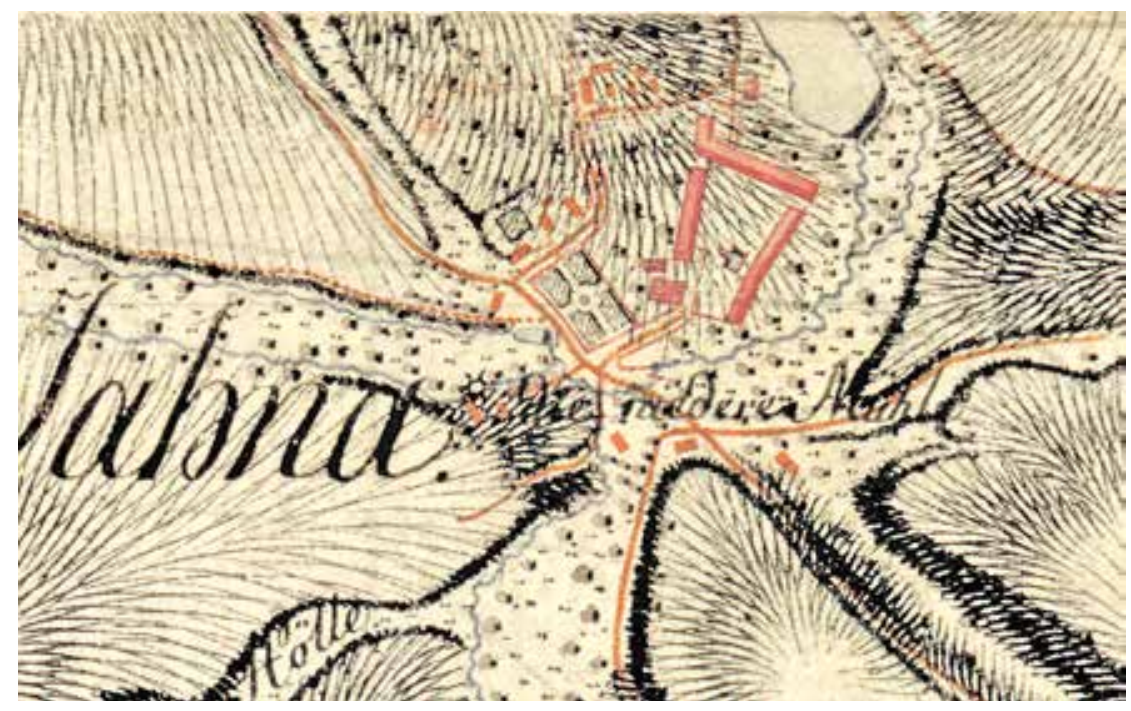

Jungviehstall, den Pferdestall, dem Kutschpferdestall, Futterkammer, Remise und Waschküche. Im Obergeschoss waren Wohnungen eingerichtet, darüber lagen Getreidespeicher und Heuboden. Auf das Dachgeschoss über dem Pferdestall war ein Uhrturm aufgesetzt. Helmuth Gröger schrieb zu diesem Neubau: „Noch niemals hatte das Rittergut während der beinahe vollendeten sieben Jahrhunderte seiner Vergangenheit eine so umfassende Erneuerung erlebt, noch niemals einen so sichtbaren Wechsel seiner äußeren Gestalt.“99

Im Rittergut wohnten, zumindest im 19. Jahrhundert, zwischen 20 und 30 Personen, wie genaue Einwohnerlisten aus den Jahren 1832 bis 1843 belegen. ${ }^{100}$ Während die herrschaftliche Familie mit Hauslehrer und Hausdamen im Herrenhaus wohnte, waren in den Wirtschaftsgebäuden auch Wohnungen für Knechte und Mägde untergebracht. 1832 wohnten auf dem Gutshof der Verwalter Johann Hermann Oehmigen, der Vogt Johann Gotthelf Hensel, der Gärtner Leberecht Müller, der Kutscher Gottlob Pinkert, die Pferdeknechte Johann Gottlieb Krauße und Carl Erler, der Ochsenknecht Gottfried Pertuch, der Saujunge Karl Schubert, die Wirtschafterin Johann Sophia Ehrbar, die Köchin Rosina Thürig, das Stubenmädchen Christiana Borsdorf, die Amme Friederike Ulrich, das Kindermädchen Christiana Mahlbach sowie die Mägde Christiana Taggesell, Christiana Platz, Friederike Schäbitz und Friederike Müller.

Die Pächterfamilie Gießmann erreichte durch eine gewinnbringende Bewirtschaftung des Ritterguts einen beträchtlichen Wohlstand. Um 1890 errichtete Julius Oskar Gießmann zwischen der nördlichen Einfahrt des Gutshofs und dem Mittelteich eine Villa als herrschaftliches Pächterwohnhaus. Das Gebäude wurde nach der Enkelin der Fideikommissinhaberin Wilhel-
Meilenblatt von Friedrich Ludwig Aster, 1801, Ausschnitt mit Gutshof und Barockgarten des Ritterguts Jahna

๑ SLUB Dresden
97 HStA Dresden, 10424, Grundherrschaft Niederjahna, Nr. 7. 98 Gröger 1937, S. 86-87. 99 Gröger 1937, S. 87

100 HStA Dresden, 10424, Grundherrschaft Niederjahna, Nr. 6. 
Abschiedsbrief von Petra Freifrau von Bischoffshausen an die Einwohner Niederjahnas, 19. Oktober 1945 ๑ Archiv ZKG mine von Heineken, der 1888 geborenen Hildegard, als „Villa Hildegard“ bezeichnet.

Südlich und östlich des Herrenhauses befand sich ein ummauertes Gartengelände, das ehemals als Barockgarten gestaltet war. Es ist erstmals auf einem Meilenblatt von Friedrich Ludwig Aster von 1801 nachgewiesen. Demnach war - ohne axialen Bezug zum Herrenhaus - ein rechteckiges, geometrisch gegliedertes Gartenkarree angelegt, das durch Wege in vier Segmente geteilt war. In der Mitte befand sich eine runde Wegekreuzung, in dessen Mitte eine Gestaltung erkennbar ist, vielleicht ein Brunnen oder eine Skulptur. Der Garten war von einer steinernen Mauer umgeben, von der noch Teile erhalten sind. Wie spätere Karten zeigen, wurde diese Gartengestaltung im 19. Jahrhundert beseitigt. Innerhalb des ummauerten Bezirks entstand ein Obst- und Gemüsegarten mit Obstbäumen und Gemüsebeeten. Dafür wurde ein

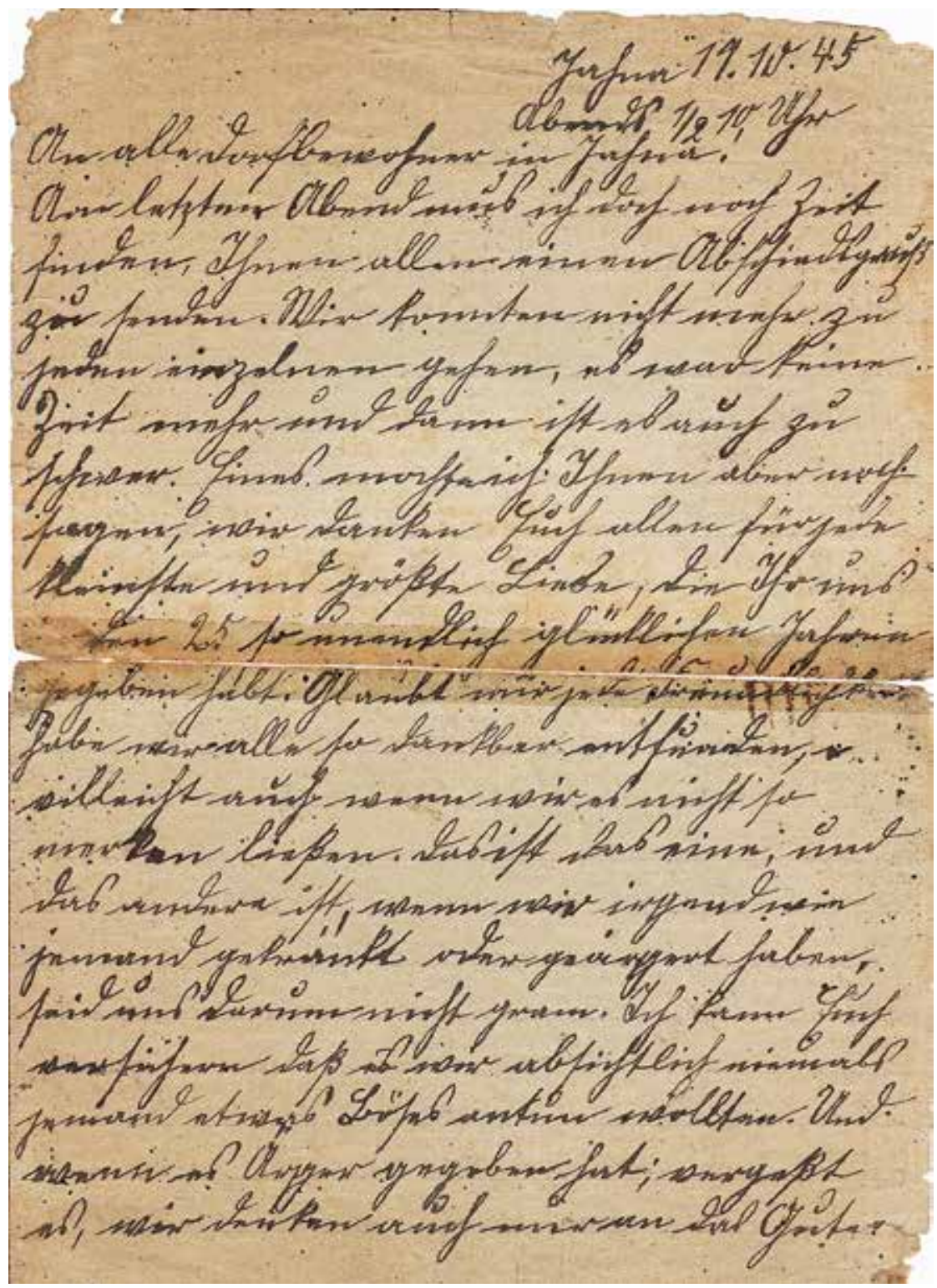

herrschaftlicher Park im Areal westlich und nördlich des Gutshofs geschaffen. Hier, in der Aue des Jahnabaches, hatte man im 17. Jahrhundert drei Teiche für die Fischzucht angelegt. Diese Teiche wurden im 19. Jahrhundert genutzt, um in ihrer Umgebung einen englischen Landschaftspark zu gestalten. Die kleine, runde Insel im Inselteich ist auf dem Meilenblatt von 1801 noch nicht vorhanden. Wahrscheinlich wurde der romantische Landschaftspark unter Carl von Ende angelegt, der 1813 das Fideikommiss Jahna übernahm und 1849 starb. Somit lässt sich für Niederjahna nachweisen, dass der Barockgarten südwestlich des Gutshofs durch einen englischen Landschaftspark nordwestlich des Gutshofs abgelöst wurde. Zwischen beiden Gartenteilen, dem Nutzgarten und dem Park, verlief die sogenannte Hofgasse, die auf das südliche Hoftor zuführte. Sie wurde nach Osten von der steinernen Gartenmauer und nach Westen von einem Parkzaun aus Eisenstäben begrenzt.

\section{Niederjahna nach 1945}

Das Dorf Niederjahna war 1945 und in den Jahren danach großen Veränderungen ausgesetzt. ${ }^{101}$ Die soziale Struktur des Ortes änderte sich nachhaltig, vor allem durch die Flüchtlinge aus Schlesien, die in Trecks aus ihrer Heimat geflüchtet waren, und Vertriebene, die in die sowjetische Besatzungszone ausgewiesen wurden. Die Einwohnerzahl stieg erheblich an. In allen nutzbaren Räumen, auch im Herrenhaus, wurden Flüchtlingswohnungen eingerichtet.

Bei der Bodenreform im Herbst 1945 erhielten Alteingesessene wie Flüchtlinge Stücke des früheren Ritterguts, sowohl Acker- und Gartenland als auch Teile der Wirtschaftsgebäude, die in Einzelsegmente geteilt und $\mathrm{zu}$ Wohnhäusern umgebaut wurden. Zudem errichtete man 13 Neubauernhäuser, fünf von ihnen wurden in den Garten des Herrenhauses hineingesetzt. Beginnend mit den Häusern an der Bergstraße, die 1959 entstanden, wurden um den alten Ortskern herum mehrere Einfamilienhaussiedlungen errichtet. So erweiterte sich die Siedlungsfläche wie auch die Einwohnerzahl deutlich. Entscheidend für diesen Ausbau Niederjahnas war, dass hier die erste Landwirtschaftliche Produktionsgenossenschaft (LPG) Sachsens gegründet wurde. Am 10. August 1952 schlossen sich Neubauern aus Niederjahna, Oberjahna und Schletta zur LPG Jahna zusammen. ${ }^{102}$ Diese hatte zunächst eine Fläche von 195 Hektar und war damit bereits im Gründungsjahr größer als das frühere Rittergut. Durch Beitritte und Zusammenschlüsse mit anderen LPGs entstand ein Großbetrieb, der mehr als 5.000 Hektar links 
und rechts der Elbe umfasste. Er befasste sich seit 1976 nur noch mit der Pflanzenproduktion, während die Tierproduktion auf Betriebe in Zehren, Löthain und Wölkisch ausgelagert war, die zuletzt die LPG Tierproduktion „Vereinte Kraft“ Zehren bildeten. Die LPG „Walter Ulbricht" Jahna mit Verwaltungssitz in Niederjahna galt als Vorzeigebetrieb sozialistischer Landwirtschaft. So wurde in den 1950er Jahren am Beispiel Jahnas für den Zusammenschluss der Bauern zu Genossenschaften geworben. Propagandistischer Höhepunkt war der „Tag des Rundfunks“, der am 5. Juli 1959 auf der Großen Wiese zwischen Nieder- und Oberjahna durchgeführt wurde. Mit einer Live-Übertragung warb der DDR-Rundfunk für die sozialistische Umgestaltung und den Eintritt in die Genossenschaften. Die unter anderem unter Beteiligung des Chefkommentators Karl-Eduard von Schnitzler (1918-2001) geplante Übertragung begann mit einem von Karl-Heinz Deregoski gedichteten Rückblick: „Wie war's in Jahna doch vordem, / für reiche Junker so bequem. / Mit vielen anderen Banausen / soff hier Baron von Bischofshausen. ${ }^{103}$ Diese Worte zeigen, mit welchem Hass die vermeintlichen „Junker“ geächtet und als Ursache allen Übels verurteilt wurden.

Das Herrenhaus wurde nach dem 19. Oktober 1945 ausgeräumt, man kann auch sagen geplündert. Die Flüchtlinge nahmen sich alles brauchbare Inventar. Unklar bleibt das Schicksal der Archivalien, der Bibliothek und sämtlicher Kunstgegenstände. Einige Möbelstücke wurden bei der „Schlossbergung“ dem Stadtmuseum Meißen übergeben. Wohin die Bildnisse geschafft wurden, von denen eine Auflistung vorliegt, die Günter Freiherr von Bischoffshausen nach der Enteignung nach der Erinnerung erstellt, ist nicht bekannt. Besonders zu bedauern sind die Verluste des Gemäldes Hans Dietrichs von Miltitz und ein Bildnis der Louise von Ende mit ihren beiden Kindern Carl und Wilhelmine, gemalt von Carl Christian Vogel von Vogelstein (1788-1868). ${ }^{104}$

Die Bilder mit Genre- und Landschaftsdarstellungen wurden der Staatlichen Porzellan-Manufaktur Meißen übergeben, wo sie sich noch heute befinden. Im Herrenhaus waren zunächst mindestens fünf Flüchtlingsfamilien untergebracht. 1947 wurde das Bürgermeisteramt aus dem Gasthof ins Herrenhaus verlegt. Seitdem befanden sich im Obergeschoss das Bürgermeisterzimmer und zwei Dienstzimmer. Der Saal wurde auch für öffentliche Veranstaltungen genutzt. 1953 zogen weitere Nutzer ein: Im Erdgeschoss wurde eine Konsum-Verkaufsstelle eröffnet, die bis Anfang der 1990er Jahre in Nutzung blieb. Danach dienten zwei Räume bis 1996 als
Speisesaal der Schulspeisung. Vier Räume im Obergeschoss nutzte die Kinderkrippe, während im Seitengebäude des Herrenhauses der Kindergarten eingerichtet wurde. Beide Einrichtungen zogen 1979 in einen Neubau an der Querstraße. Im Dachgeschoss befanden sich eine Wohnung sowie eine öffentliche Nähstube. Der Lehrer Fritz Nitzsche, der 1960 die Entwicklung des Dorfes beschrieb, bemerkte dazu stolz „Alle haben Platz!“. ${ }^{105}$ Trotz der intensiven Nutzung blieben viele historische Elemente erhalten, etwa die Treppen und Türen, die unverändert blieben. Die Wappen am Hauptportal hatte man überputzt, während die Wappen- und Schrifttafel am Ostgiebel sichtbar blieb.

Infolge der Bodenreform versuchte man, die Gutsanlage unkenntlich zu machen. So wurden die Hoftore des Gutshofes beseitigt und ein Teil der Winkelscheune abgebrochen. Die Vorgabe, den herrschaftlichen Charakter zu beseitigen, erfüllte man durch Abbruch des Mittelteils der östlichen Hofbebauung, denn dort erhoben sich Giebel und Uhrturm. Seitdem klaffte an der Ostseite eine Lücke. Während in den 1950er Jahren der Gutshof noch als einheitliches Hofgebilde wahrzunehmen war, veränderte sich durch den Bau einer durchgehenden Straße, die Parzellierung des Hoflandes und die Abtrennung der Grundstücke durch Zäune und Hecken das Bild entscheidend. Die äußere Scheune wurde 1957 abgebrochen und durch einen kleineren Neubau ersetzt, der erst als Wäscherei und später als Speisesaal diente. Das hoch aufragende Dach der Winkelscheune wurde 1965 abgetragen.

Der Gartenbereich um das Herrenhaus verändert sich deutlich, denn in den Garten wurden mehrere Neubauernhäuser hineingesetzt. Die ursprüngliche Ausdehnung lässt sich jedoch noch heute anhand der Bruchsteinmauer erahnen, die einst das gesamte Gelände umgab und die in Teilen noch vorhanden ist. Von älteren Gestaltungselementen dieses Gartenteils blieb nichts erhalten. Im Park waren die Eingriffe geringer. Der Zaun, der den Park umgab, wurde abgetragen. Man setzte zwei Baracken (,Bungalows“) hinein, eine 1968 für die Gemeindeschwester (heute Dorfclub) und 1989 eine als Wäsche-Annahmestelle (heute Anglerclub). Im westlichen Teil befindet sich seit 1986 ein Damwildgehege. Die größte Veränderung vollzog sich aber durch die ausbleibende Pflege. So verwandelte sich der einst gepflegte Park in einen dicht bewachsenen Auenwald. Der Mühlenteich wurde 1974 zugeschüttet, so dass heute nur noch zwei der drei Teiche vorhanden sind.

Die LPG Jahna wurde 1991 aufgelöst, die letzten Vermögensreste 1997 liquidiert. Heute bestehen verschiedene Nachfolgebetriebe. Mit Ausnahme
$101 \mathrm{Zu}$ den Entwicklungen nach 1945 vgl. v. a. 800 Jahre Niederjahna. Ein Streifzug durch die Geschichte. Niederjahna 2005, S. 9-64.

102 Die Geschichte der LPG Jahna bedarf noch einer Aufarbeitung, die vor allem deshalb geboten erscheint, weil es sich hier um die früheste LPG-Gründung in Sachsen handelt und an diesem Beispiel die Entwicklung der Landwirtschaft in der DDR über fast vier Jahrzehnte abgehandelt werden könnte. Als gedruckte Zeitdokumente sind heranzuziehen: Friedrich Martin: Freiheit, die wir meinen. Berlin 1977; Wolfgang Hübner: Leben und Sterben einer LPG oder $40 \mathrm{Jah}-$ re meines Arbeitslebens. o. O. [um 1998/99].

103 Manuskript der Rundfunksendung, erstellt am 24 Juni 1959 von der Redaktion Landwirtschaft des DDR-Rundfunks, im Besitz von Dr. Matthias Donath.

104 Vgl. Ahnenbilder in Jahna, aufgezeichnet am 10. 11. 1960 von Günther v. Bischoffshausen aus der Erinnerung, im Besitz von Dr. Matthias Donath.

105 Handschriftliche Rückschau auf die Jahre 1945 bis 1960, im Besitz von Dr. Matthias Donath. 
Herrenhaus Niederjahna, Eingangshalle und Saal Foto: Matthias Donath
Weihe der Kapelle im Herrenhaus Niederjahna, 2017 Foto: Christiane Schiemank

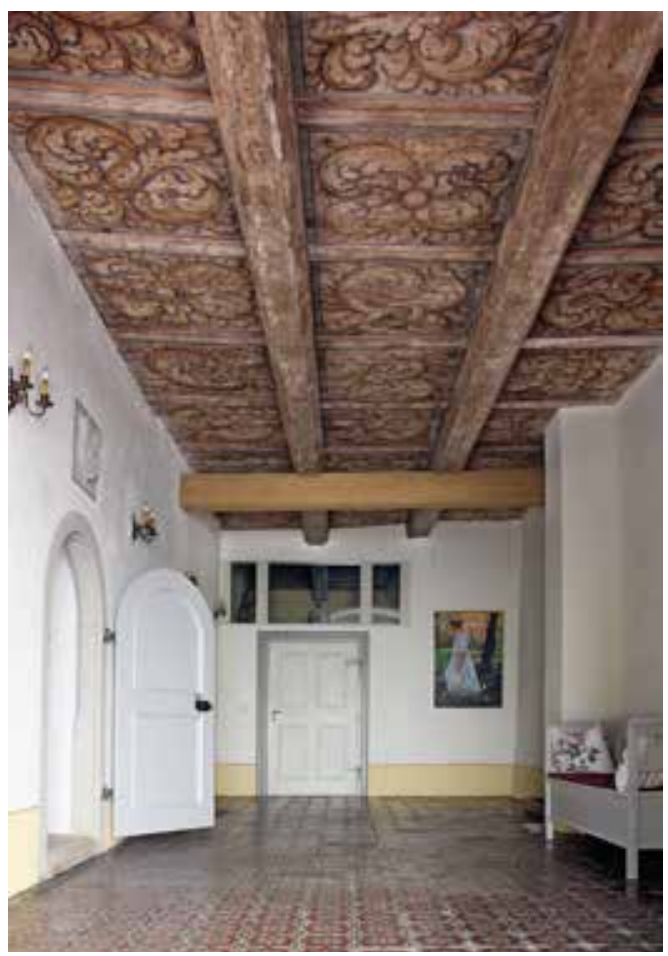

der großen, noch von der LPG erbauten Kuhställe am Westrand des Dorfes wird aber heute in Niederjahna selbst keine Landwirtschaft mehr betrieben. Das Dorf ist zu einem reinen Wohnort geworden. Es hat auch seine Stellung als Verwaltungsmittelpunkt verloren, denn 1996 wurde die Gemeindeverwaltung infolge des Zusammenschlusses der Gemeinden Jahna-Löthain, Krögis und Planitz-Deila zur Gemeinde Käbschütztal nach Krögis verlegt.

2010 erwarb ich das Herrenhaus mit Seitengebäude (Wintergarten) und einen Teil des frühe-

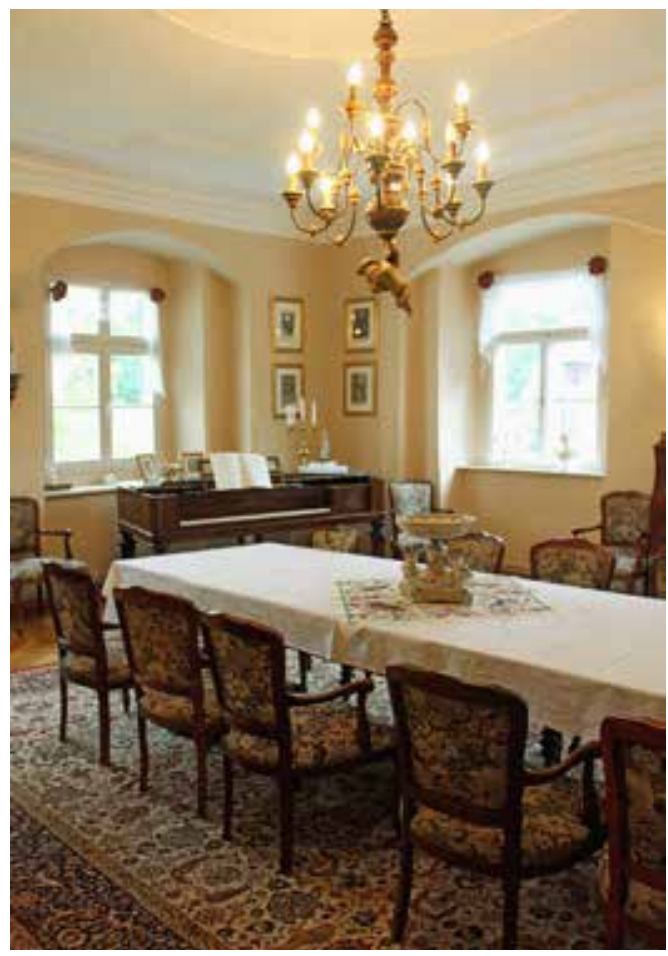

ren Gartens. Seit 2013 wird das Herrenhaus als Wohnhaus der Familie und Unternehmenssitz genutzt. Im Saal werden gelegentlich Konzerte veranstaltet, außerdem finden hier Veranstaltungen der Evangelisch-Lutherischen Kirchgemeinde St. Afra Meißen statt, so der Kindertreff für die Christenlehrekinder der Afranischen Dörfer und die „Niederjahnaer Gespräche“, eine Gesprächsreihe mit christlichem Hintergrund. Am 7. August 2017 wurde im Erdgeschoss die evangelisch-lutherische Kapelle St. Donatus geweiht.

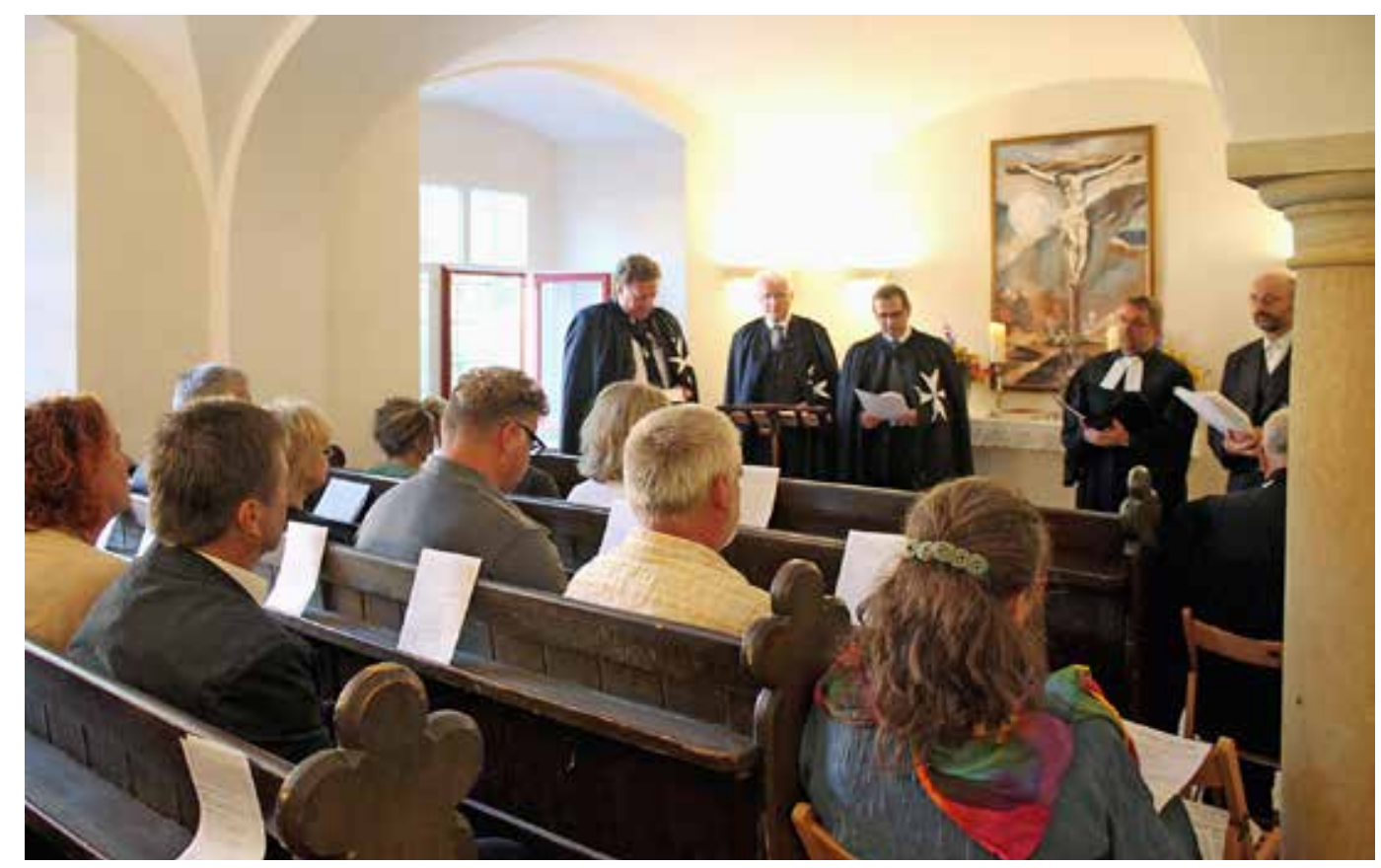

